$1 / 10 / 24-94 \% 20$

SANDIA REPORT

SAND94-1498 - UC-405

Unlimited Release

Printed October 1994

\title{
CTH Analyses of Steel Rod Penetration into Aluminum and Concrete Targets with Comparisons to Experimental Data
}

\author{
L. N. Kmetyk, P. Yarrington
}

Propared by

Sandla National Laboratorles

Albuquorque, Now Mexlco 87185 and Lvermore, Callfornia 94550

for the Unilod Statos Depertment of Energy

under Controct DE-ACO4-OAAL85000

Approved for public release; distribution is unlimited.

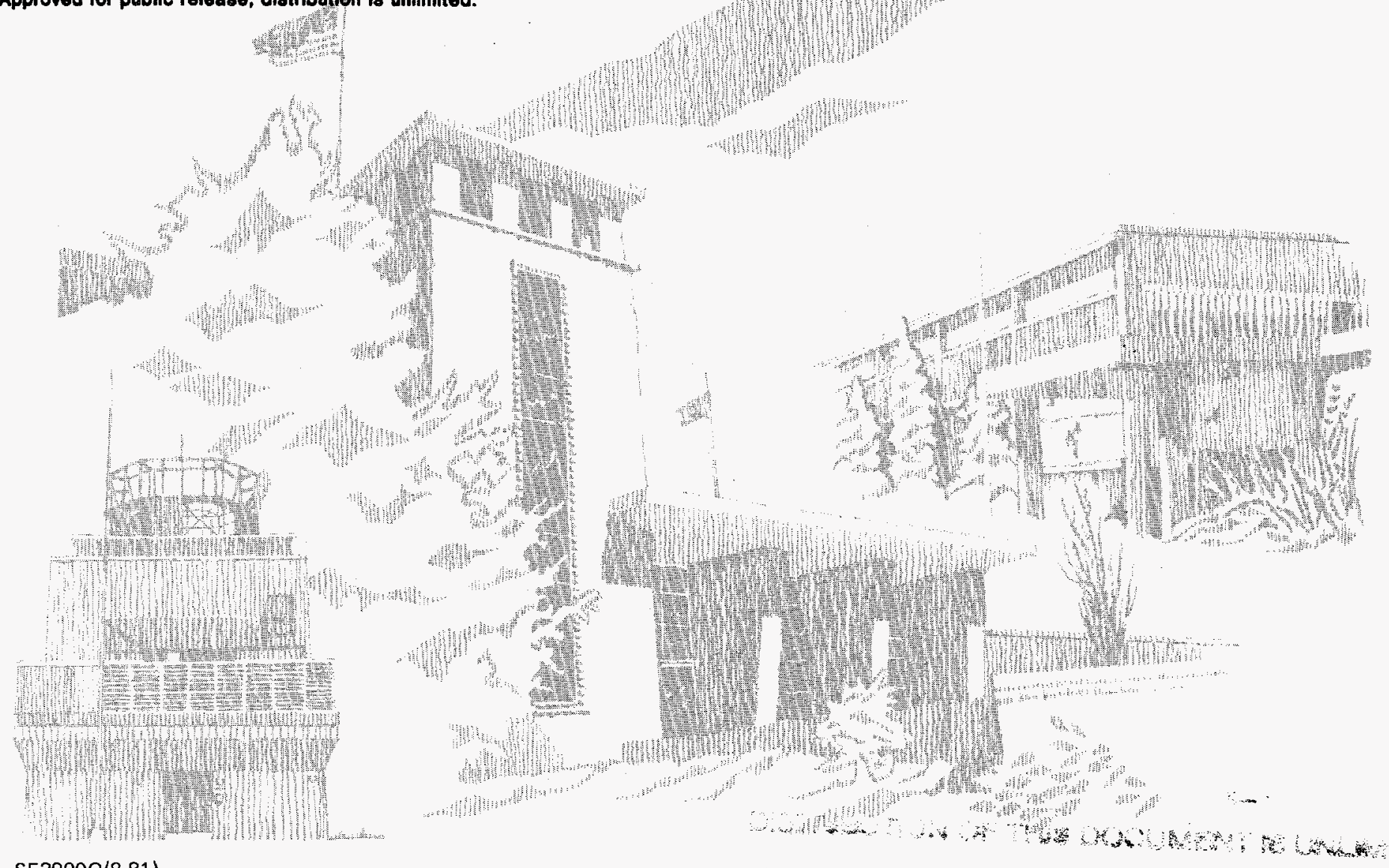


Isoued by Sandia National Laboratories, operated for the United States Department of Energy by Sandia Corporation.

NOTICE: This report was prepared as an account of work sponsored by an agency of the United States Government. Neither the United States Government nor any agency thereof, nor any of their employees, nor any of their contractors, subcontractors, or their employees, makes any warranty, express or implied, or assumes any legal liability or responsibility for the accuracy, completeness, or usefulness of any information, apparatus, product, or process disclosed, or represents that its use would not infringe privately owned rights. Reference herein to any specific commercial product, process, or service by trade name, trademark, manufacturer, or otherwise, does not necessarily constitute or imply its endorsement, recommendation, or favoring by the United States Government, any agency thereof or any of their contractors or subcontractors. The views and opinions expressed herein do not necessarily state or reflect those of the United States Government, any agency thereof or any of their contractors.

Printed in the United States of America. This report has been reproduced directly from the best available copy.

Available to DOE and DOE contractors from Office of Scientific and Technical Information PO Box 62

Oak Ridge, TN 37831

Prices available from (615) 576-8401, FTS 626-8401

Available to the public from

National Technical Information Service

US Department of Commerce

5285 Port Royal Rd

Springfield, VA 22161

NTIS price codes

Printed copy: A04

Microfiche copy: A01 


\section{DISCLAIMER}

Portions of this document may be illegible in electronic image products. Images are produced from the best available original document. 


\title{
CTH Analyses of Steel Rod Penetration into Aluminum and Concrete Targets with Comparisons to Experimental Data
}

\author{
L. N. Kmetyk \\ Thermal/Hydraulic Analysis Department \\ P. Yarrington \\ Computational Physics and Mechanics Department \\ Sandia National Laboratories \\ Albuquerque, NM 87185
}

\begin{abstract}
Calculational results are presented here for a class of intermediate-velocity penetration problems. The problems of interest involve penetration of moderate-strength target materials by high-strength projectiles. Two series of metal penetration experiments and a series of concrete slab perforation tests were simulated in this study. The computer code used for the calculations was the CTH code, which employs a recently-developed "boundary layer" algorithm for treating penetration problems such as these.
\end{abstract}

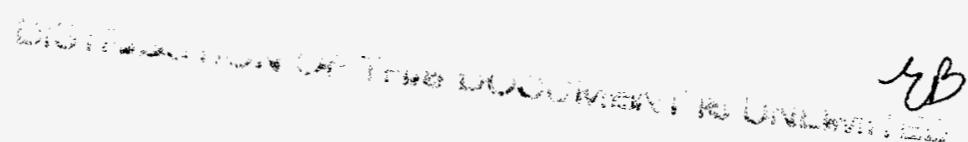




\section{Contents}

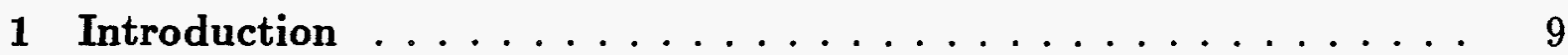

2 Penetration of Aluminum Targets by Ogival-Nosed Steel Rods . . 10

2.1 Experiment Description $\ldots \ldots \ldots \ldots \ldots$

2.2 CTH Model Input $\ldots \ldots \ldots \ldots \ldots \ldots$

2.3 Calculational Results . . . . . . . . . . . . . . . 14

3 Penetration of Aluminum Targets by Hemispherical-Nosed Steel Rods 21

3.1 Experiment Description $\ldots \ldots \ldots \ldots \ldots 21$

3.2 CTH Model Input . . . . . . . . . . . . . . . . . . . 24

3.3 Calculational Results $\ldots \ldots \ldots \ldots \ldots$

4 Penetration of Concrete Targets by Ogival-Nosed Steel Rods . . . 32

4.1 Experiment Description $\ldots \ldots \ldots \ldots . \ldots \ldots$

4.2 CTH Model Input . . . . . . . . . . . . . . . . . . 34

4.3 Calculational Results $\ldots \ldots \ldots \ldots \ldots \ldots$

5 Summary and Conclusions $\ldots \ldots \ldots \ldots \ldots \ldots$

Bibliography . . . . . . . . . . . . . . . . 46

A CTH Input Model for Penetration of Aluminum Targets by OgivalNosed Steel Rods at $1258 \mathrm{~m} / \mathrm{s} \ldots \ldots \ldots$. . . . . . . 47

B CTH Input Model for Penetration of Aluminum Targets by HemisphericalNosed Steel Rods at $1009 \mathrm{~m} / \mathrm{s}$

C CTH Input Model for Penetration of Concrete Targets by OgivalNosed Steel Rods at $1000 \mathrm{~m} / \mathrm{s}$ 


\section{List of Figures}

2.1.1 Projectile Geometry - Ogival-Nosed Rod for 7075-T651 Aluminum Target Tests . . . . . . . . . . . . . . . . . . . . . 11

2.1.2 Compression Stress-Strain Curves for the 7075-T651 Aluminum Target Ma-

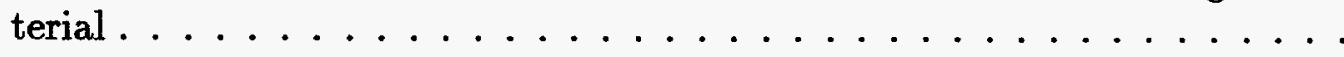

2.2.1 Initial Configuration for CTH Analyses - Ogival-Nosed Rods Penetrating 7075-T651 Aluminum Targets . . . . . . . . . . . . . . .

2.3.1 Penetration Depth vs Impact Velocity - Ogival-Nosed Rods Penetrating 7075-T651 Aluminum Targets . . . . . . . . . . . . . . . . . .

2.3.2 Predicted Final Configuration for Ogival-Nosed Rod Penetrating 7075-T651 Aluminum Targets at $1258 \mathrm{~m} / \mathrm{s}$ Impact Velocity . . . . . . . . . . . .

2.3.3 Axial Stress Contours Predicted by CTH during Penetration for $1258 \mathrm{~m} / \mathrm{s}$ Impact Velocity (A: 0.5kbar, B: 1kbar, C: 5kbar, D: 10kbar) - Ogival-Nosed Rod Penetrating 7075-T651 Aluminum Target . . . . . . . . . .

2.3.4 Rigid-Body Decelerations Predicted by CTH for Various Impact Velocities - Ogival-Nosed Rods Penetrating 7075-T651 Aluminum Targets . . . . . 20

3.1.1 Projectile Geometry - Hemispherical-Nosed Rod for 6061-T651 Aluminum Target Tests . . . . . . . . . . . . . . . . . . . 22

3.1.2 Stress-Strain Data for the 6061-T651 Target Material . . . . . . . . . 23

3.2.1 Initial Configuration for CTH Analyses - Hemispherical-Nosed Rods Penetrating 6061-T651 Aluminum Targets . . . . . . . . . . . . . .

3.3.1 Penetration Depth Predicted by CTH for Various Impact Velocities and Friction Factors - Hemispherical-Nosed Rods Penetrating 6061-T651 Aluminum Targets . . . . . . . . . . . . . . . . .

3.3.2 Final Configuration Predicted by CTH for a Hemispherical-Nosed Rod Penetrating a 6061-T651 Aluminum Target at an Impact Velocity of $1009 \mathrm{~m} / \mathrm{s}$

3.3.3 Rigid-Body Decelerations Predicted by CTH for Various Impact Velocities

- Hemispherical-Nosed Rods Penetrating 6061-T651 Aluminum Targets . .

3.3.4 Penetration Depth Predicted by CTH for Ogival- and Hemispherical-Nosed Rods of Equal Mass Penetrating 7075-T651 Aluminum Targets . . . . . 30

3.3.5 Rigid-Body Decelerations Predicted by CTH for Ogival- and HemisphericalNosed Rods of Equal Mass Penetrating 7075-T651 Aluminum Targets at $1258 \mathrm{~m} / \mathrm{s}$ Impact Velocity

4.1.1 Projectile Geometry - Ogival-Nosed Rods for 140MPa Concrete Target Tests 33

4.1.2 Materials Property Data for the $48 \mathrm{MPa}$ and $140 \mathrm{MPa}$ Concrete Target Materials ....................... 35 
4.2.1 Initial Configuration for CTH Analyses - Ogival-Nosed Rods Penetrating 140MPa Concrete Targets . . . . . . . . . . . . . . . . .

4.3.1 Residual Velocity Predicted by CTH for Various Impact Velocities and Friction Factors - Ogival-Nosed Rods Penetrating 140MPa Concrete Targets .

4.3.2 Penetrator and Target Configurations Predicted by CTH - Ogival-Nosed Rod Penetrating 140MPa Concrete Target at an Impact Velocity of $1000 \mathrm{~m} / \mathrm{s} 39$

4.3.3 Rigid-Body Decelerations Predicted by CTH for Various Impact Velocities - Ogival-Nosed Rods Penetrating 140MPa Concrete Targets . . . . . . . 41

4.3.4 Residual Velocity Predicted by CTH for Various Impact Velocities and Calculational Zone Sizes - Ogival-Nosed Rods Penetrating 140MPa Concrete Targets . . . . . . . . . . . . . . . . . . .

4.3.5 Rigid-Body Decelerations Predicted by CTH for an Impact Velocity of $1000 \mathrm{~m} / \mathrm{s}$ with Different Zone Sizes - Ogival-Nosed Rods Penetrating 140MPa Concrete Targets . . . . . . . . . . . . . . . . .

4.3.6 Residual Velocity Predicted by CTH when Concrete Material Properties are Varied - Ogival-Nosed Rods Penetrating 140MPa Concrete Targets at an Impact Velocity of $1000 \mathrm{~m} / \mathrm{s} \ldots \ldots \ldots \ldots \ldots$ 


\section{List of Tables}

2.1.1 Data Summary - Ogival-Nosed Rods and 7075-T651 Aluminum Target Tests 15

2.2.1 Material Properties Used in CTH Analyses for Ogival-Nosed Rods Penetrating 7075-T651 Aluminum Targets . . . . . . . . . . . . . .

3.1.1 Data Summary - Hemispherical-Nosed Rods and 6061-T651 Aluminum Tar-

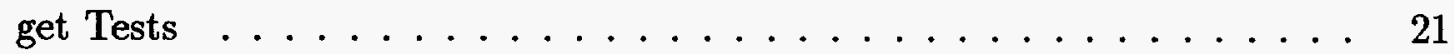

3.2.1 Material Properties Used in CTH Analyses for Hemispherical-Nosed Rods Penetrating 6061-T651 Aluminum Targets . . . . . . . . . . . 24

4.1.1 Data Summary - Ogival-Nosed Rods and 140MPa Concrete Target Tests . 32

4.2.1 Material Properties Used in CTH Analyses of Ogival-Nosed Rods Penetrating $140 \mathrm{MPa}$ Concrete Targets . . . . . . . . . . . . . . . . 


\section{Introduction}

The calculations presented here were done as part of a calculational benchmarking study to evaluate the capability of current calculational methods for predicting effects associated with penetration of low-strength targets by high-strength projectiles, in a velocity regime where the penetrator remains essentially elastic. As an initial benchmarking activity under this program, two series of metal penetration experiments and a series of concrete slab perforation tests were simulated. The metal penetration problems involved high-strength steel projectiles with two different nose geometries impacting thick cylindrical targets of relatively soft aluminum alloys. The concrete perforation problems again involved high-strength steel projectiles, with the targets in this case being slabs of unreinforced concrete.

The computer code used for the calculations was the CTH [1] code, which was developed to treat a wide range of continuum dynamics problems involving intense, impulsive loading of materials. The calculations used a relatively new "boundary layer algorithm" $[2,3]$ in $\mathrm{CTH}$ to treat the interface between penetrator and target. This algorithm eliminates the artificial erosion of penetrator material that can occur in Eulerian code calculations.

The work presented here involves CTH simulations of the following problems:

1. penetration of aluminum targets by steel ogival-nosed rods [4] (Section 2),

2. penetration of aluminum targets by steel hemispherical-nosed rods [5] (Section 3),

3. penetration of concrete targets by steel ogival-nosed rods [6] (Section 4).

Each section includes a brief description of the experiments, the CTH input model and parameters used, and comparisons of calculational results to the test data. Overall conclusions are summarized in Section 5. 


\section{Penetration of Aluminum Targets by Ogival-Nosed Steel Rods}

\subsection{Experiment Description}

Forrestal et al. [4] conducted terminal-ballistic experiments involving $0.711 \mathrm{~cm}$-diameter, $25 \mathrm{gm}, 3.0$ caliber-radius-head (CRH), ogival-nosed steel rods of length $L=7.112 \mathrm{~cm}$ impacting 7075-T651 aluminum cylindrical targets.

The projectile shape is shown in Figure 2.1.1. Projectiles were T-200 maraging steel with density $\rho_{p}=8.02 \mathrm{gm} / \mathrm{cc}$ and a nominal yield stress of $1.72 \mathrm{GPa}$. The range of impact velocities was between 370 and $1260 \mathrm{~m} / \mathrm{s}$, as indicated in Table 2.1.1. Impact was normal to within $2^{\circ}$.

The targets were cut from $15.2 \mathrm{~cm}$-diameter bars, wbp the target length for each test is given in Table 2.1.1. In addition, axial specimens of this bar stock were machined for large-strain compression tests. Figure 2.1.2 shows data for compression tests at a strain rate of $10^{-1} / \mathrm{s}$, along with a power law data fit discussed in Ref. [4].

For the projectile impact experiments, post-test penetration depths were measured from in-material X-ray photographs, with results summarized in Table 2.1.1.

\subsection{CTH Model Input}

The CTH calculations were performed using 2D cylindrical coordinates. Figure 2.2.1. shows CTH material plots of the initial condition for these calculations.

Most of the calculations were performed with a basecase zoning of $75 \times 825$ cells. The $x$-direction mesh was started at $x=0$, the axis of symmetry, and extended to a radius of $1.0 \mathrm{~cm}$ using 25 uniform cells of $0.04 \mathrm{~cm}$ width. (Recall that the rod outer radius was $0.3555 \mathrm{~cm}$.) This was followed by 50 more cells of increasing (at $\sim 5 \%$ rate) size in the $x$-direction to an outer radius of $\sim 8.5 \mathrm{~cm}$ to cover the entire target. In the $y$-direction, the mesh was started at $y=-24 \mathrm{~cm}$, wbp $y=0$ was taken as the impact surface of the target, and the bottom of the cylindrical target was at $y=-22.9 \mathrm{~cm}$. The mesh extended to $+9 \mathrm{~cm}$ in the $y$-direction using 825 uniform cells of $0.04 \mathrm{~cm}$ width. Thus, a subgrid of square cells covered the penetration region, with the cell size being $0.04 \mathrm{~cm}$ in both the $x$ - and $y$-directions.

The various material properties used in the CTH calculations for these tests are given in Table 2.2.1. Both the penetrator and the target were modelled with analytic MieGruneisen equations of state. The penetrator was modelled as an elastic-perfectly plastic material. The aluminum target was modelled using the Johnson-Cook viscoplastic model [7], with material constants based on a fit to the data shown in Figure 2.1.2 for 7075-T651 aluminum.

The density and yield strength of the steel were increased by a factor 


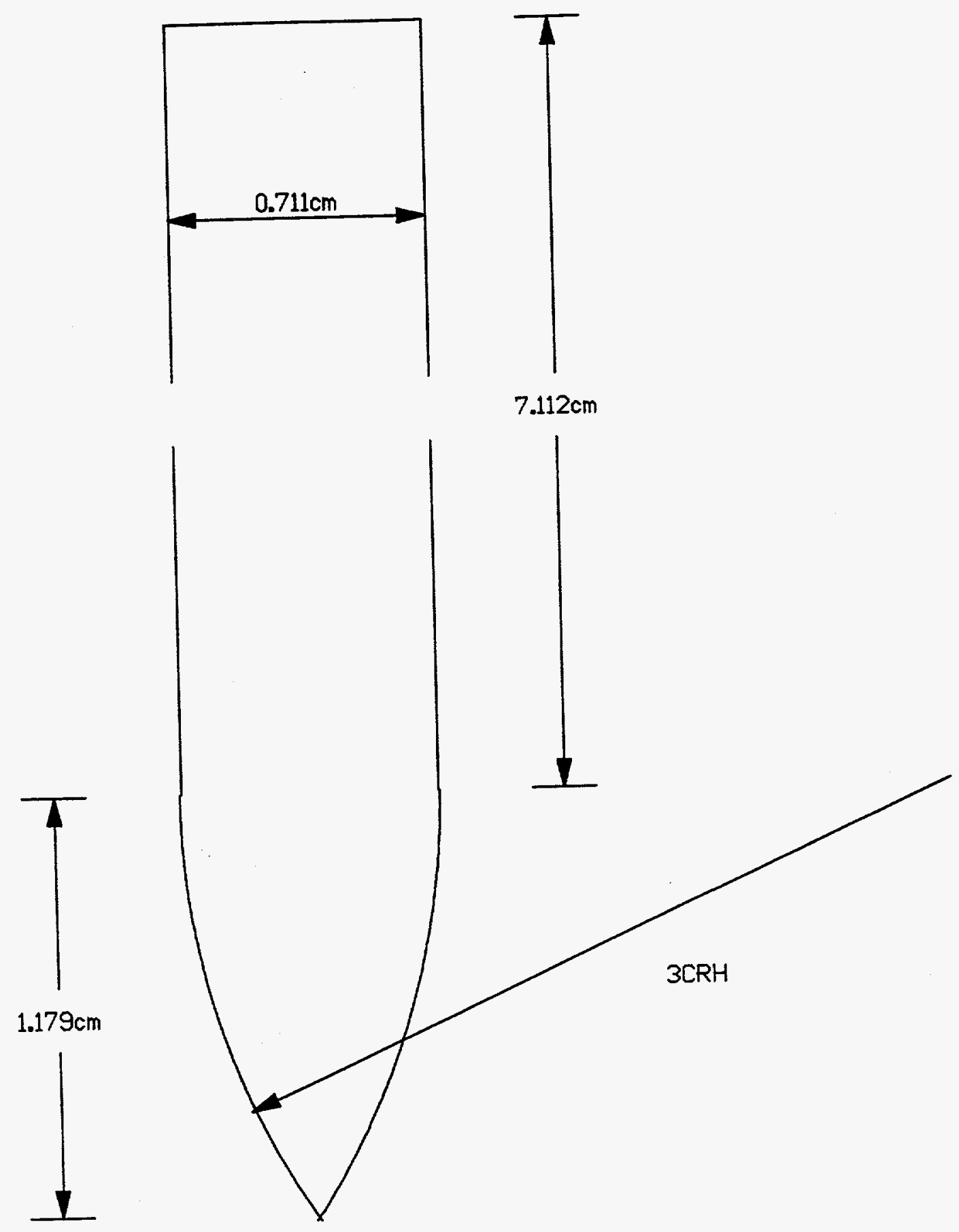

Figure 2.1.1. Projectile Geometry - Ogival-Nosed Rod for 7075-T651 Aluminum Target Tests 


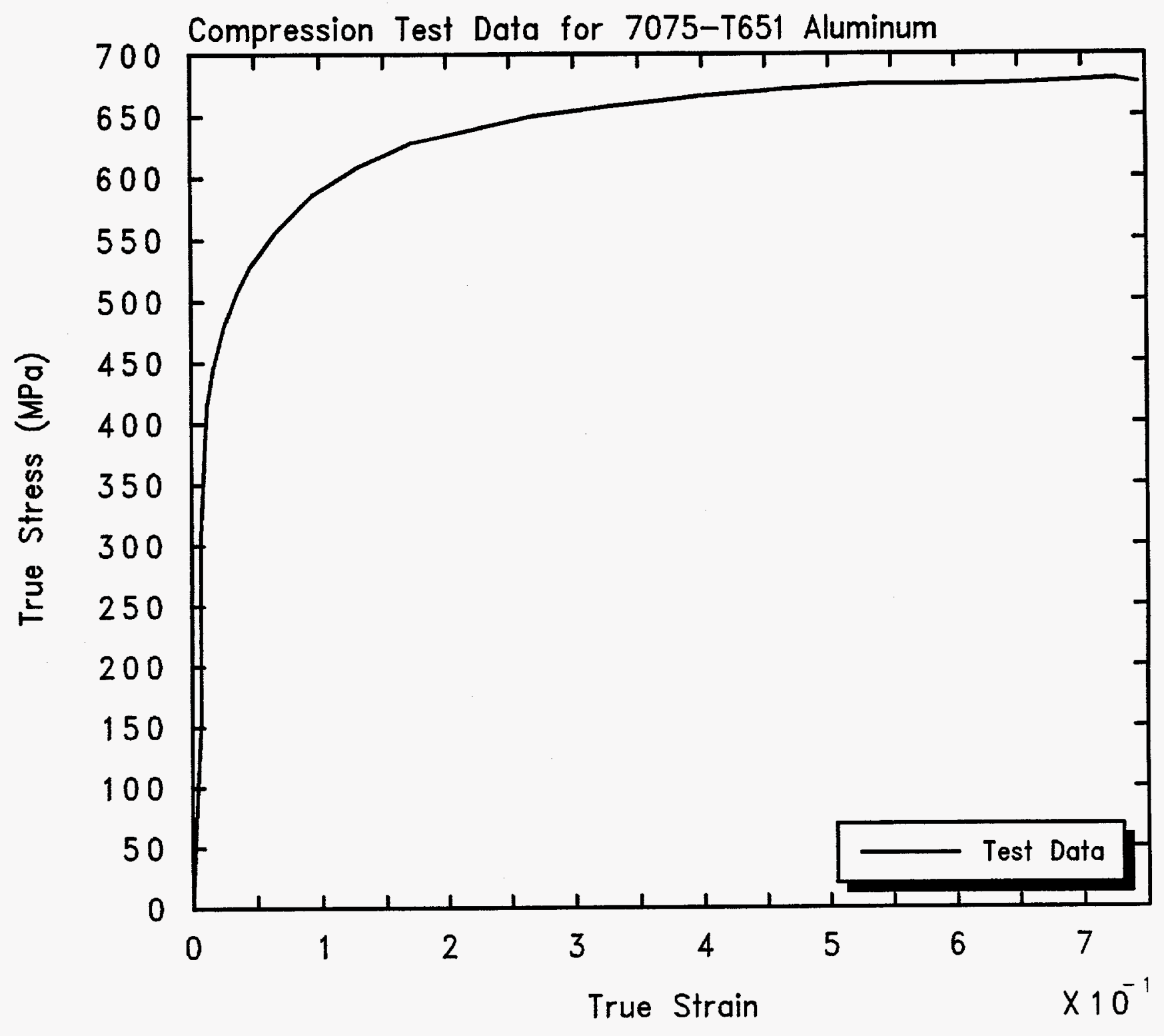

Figure 2.1.2. Compression Stress-Strain Curves for the 7075-T651 Aluminum Target Material 

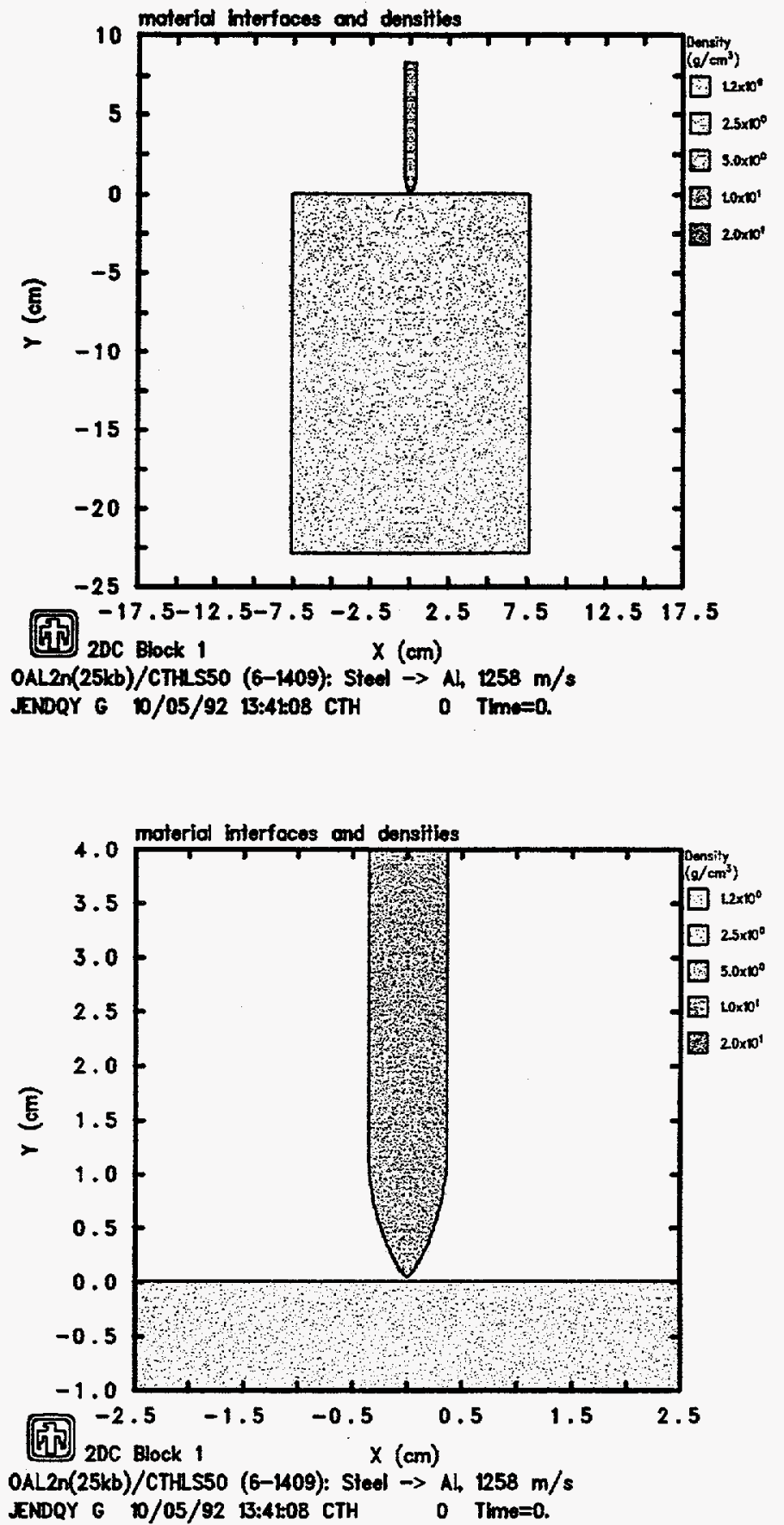

Figure 2.2.1. Initial Configuration for CTH Analyses - Ogival-Nosed Rods Penetrating 7075-T651 Aluminum Targets 


$$
\left(\frac{\left(r_{o}+w_{s l} / 2\right)}{r_{o}}\right)^{2}
$$

to account for boundary layer effects, wbp $r_{o}$ is the penetrator outer radius and $w_{s l}$ is the slip layer thickness. (This correction can be made automatically as an option in the boundary layer algorithm input [2].) Both the boundary layer thickness, $w_{b l}$, and the slip layer thickness, $w_{s l}$, were specified to be $0.08 \mathrm{~cm}$, i.e., twice the zone size in the projectile/target interaction region.

The penetration calculations were performed with the nonequilibrium, multi-material temperature and multi-material pressure modelling options in CTH, with the highresolution interface tracker. Velocity was specified to be convected conserving momentum exactly and discarding any kinetic energy discrepancies. Artificial viscosity was used, with default values for the linear and quadratic coefficients, and the shear artificial viscosity increased to 0.1 . The region around the penetrator and target was modelled as void.

\subsection{Calculational Results}

Calculations were run for the five different values of impact velocity listed in Table 2.1.1. Results of calculations with $\Delta x=\Delta y=0.04$ in the penetration region and $w_{b l}=w_{s l}=0.08$ are shown in Figure 2.3.1. This plot gives penetration depth as a function of impact velocity. The experimental data [4] are also shown. Both the calculational results and the experimental data are represented by plot symbols, with straight-line segments connecting the symbols to highlight overall trends.

Figure 2.3.1 also shows the effect of varying the friction coefficient $f$ between 0.0 and 0.12 . In general, the calculations predict somewhat deeper penetration depths than were observed in the tests.

Figure 2.3.2 illustrates the predicted shape of the penetrator and cavity at $400 \mu \mathrm{s}$, when the penetrator has come to a full stop for an impact velocity of $1258 \mathrm{~m} / \mathrm{s}$. Note that the penetrator shows essentially no permanent deformation, which is consistent with the test observations [4].

Axial stress contours predicted at four different times during the penetration process are depicted in Figure 2.3.3. The contours show an essentially steady-state stress distribution on the penetrator developing after a few noselengths of penentration.

Figure 2.3.4 presents the rigid-body decelerations calculated for these tests as a function of both velocity, in the upper plot, and depth of penetration, in the lower plot. (The rigid-body decelerations plotted in this report are the time derivatives of the massweighted average velocity of the penetrator material, smoothed using a bell-shaped function with a $0.05 \mathrm{~ms}$ time constant.) For the higher impact velocities above $\sim 400 \mathrm{~m} / \mathrm{s}$, the decelerations all fall on the same deceleration $v s$ velocity curve and reach a reasonably 
Table 2.1.1. Data Summary - Ogival-Nosed Rods and 7075-T651 Aluminum Target Tests

\begin{tabular}{|c|c|c|c|c|c|c|}
\hline $\begin{array}{l}\text { Shot } \\
\text { number }\end{array}$ & $\begin{array}{l}\text { Mass } \\
(\mathrm{gm})\end{array}$ & $\begin{array}{c}V_{0} \\
(\mathrm{~m} / \mathrm{s})\end{array}$ & $\begin{array}{c}\alpha \dagger \\
\text { (degrees) }\end{array}$ & $\begin{array}{c}\beta \dagger \\
\text { (degrees) }\end{array}$ & $\begin{array}{c}P \ddagger \\
(\mathrm{cm})\end{array}$ & $\begin{array}{l}\text { Target length } \\
(\mathrm{cm})\end{array}$ \\
\hline $6-1397$ & 24.8 & 372 & 0.4 & 0.8 & 2.6 & 12.7 \\
\hline $6-1398$ & 24.7 & 695 & 1.9 & 1.7 & 7.0 & 12.7 \\
\hline $6-1391$ & 24.8 & 978 & 0 & 0 & 12.7 & 17.8 \\
\hline $6-1402$ & 24.7 & 1067 & 0.1 & 0.7 & 14.7 & 22.9 \\
\hline $6-1409$ & 24.8 & 1258 & 1.3 & 1.1 & 20.9 & 22.9 \\
\hline
\end{tabular}

Table 2.2.1. Material Properties Used in CTH Analyses for Ogival-Nosed Rods Penetrating 7075-T651 Aluminum Targets

$\begin{array}{lcc}\text { Property } & \begin{array}{c}\text { Penetrator } \\ \text { (Steel) }\end{array} & \begin{array}{c}\text { Target } \\ \text { (Aluminum) }\end{array} \\ & & \\ \text { Density, } \rho\left(\mathrm{gm} / \mathrm{cm}^{3}\right) & 8.02 & 2.70 \\ \text { Sound speed, } C_{S}(\mathrm{~cm} / \mathrm{s}) & 4.610 \times 10^{5} & 5.380 \times 10^{5} \\ U_{s}-U_{p} \text { slope, } S & 1.73 & 1.337 \\ \text { Gruneisen coefficient, } \Gamma & 1.67 & 2.100 \\ \text { Specific heat, } C_{V}(\mathrm{erg} / \mathrm{gm}-\mathrm{eV}) & 5.34 \times 10^{10} & 1.02 \times 10^{11} \\ & & \\ \text { Poisson's ratio, } \nu & 0.3 & 0.33 \\ \text { Yield stress, } Y\left(\text { dynes } / \mathrm{cm}^{2}\right) & 17.2 \times 10^{9} & \\ \text { Johnson-Cook model constants } & & \\ A\left(\text { dynes } / \mathrm{cm}^{2}\right) & & 4.48 \times 10^{9} \\ B\left(\text { dynes } / \mathrm{cm}^{2}\right) & & 2.95 \times 10^{8} \\ C\left(\text { dynes } / \mathrm{cm}^{2}\right) & & 0 \\ n & & 0.39205 \\ T_{M}(\mathrm{eV}) & & 0.0668 \\ & & \\ P_{F R A C}\left(\text { dynes } / \mathrm{cm}^{2}\right) & -35 \times 10^{9} & -5 \times 10^{9}\end{array}$




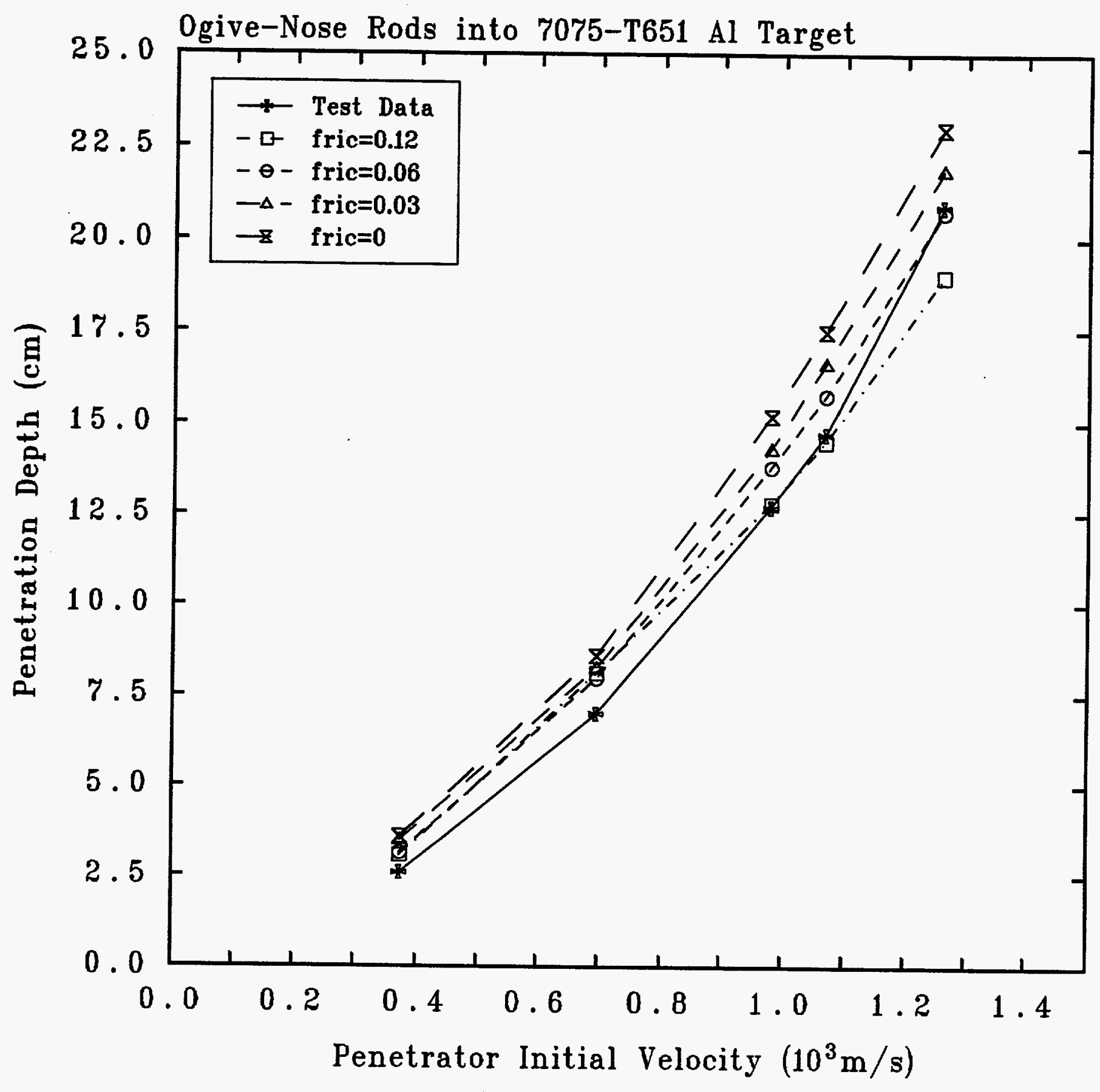

Figure 2.3.1. Penetration Depth vs Impact Velocity - Ogival-Nosed Rods Penetrating 7075-T651 Aluminum Targets 


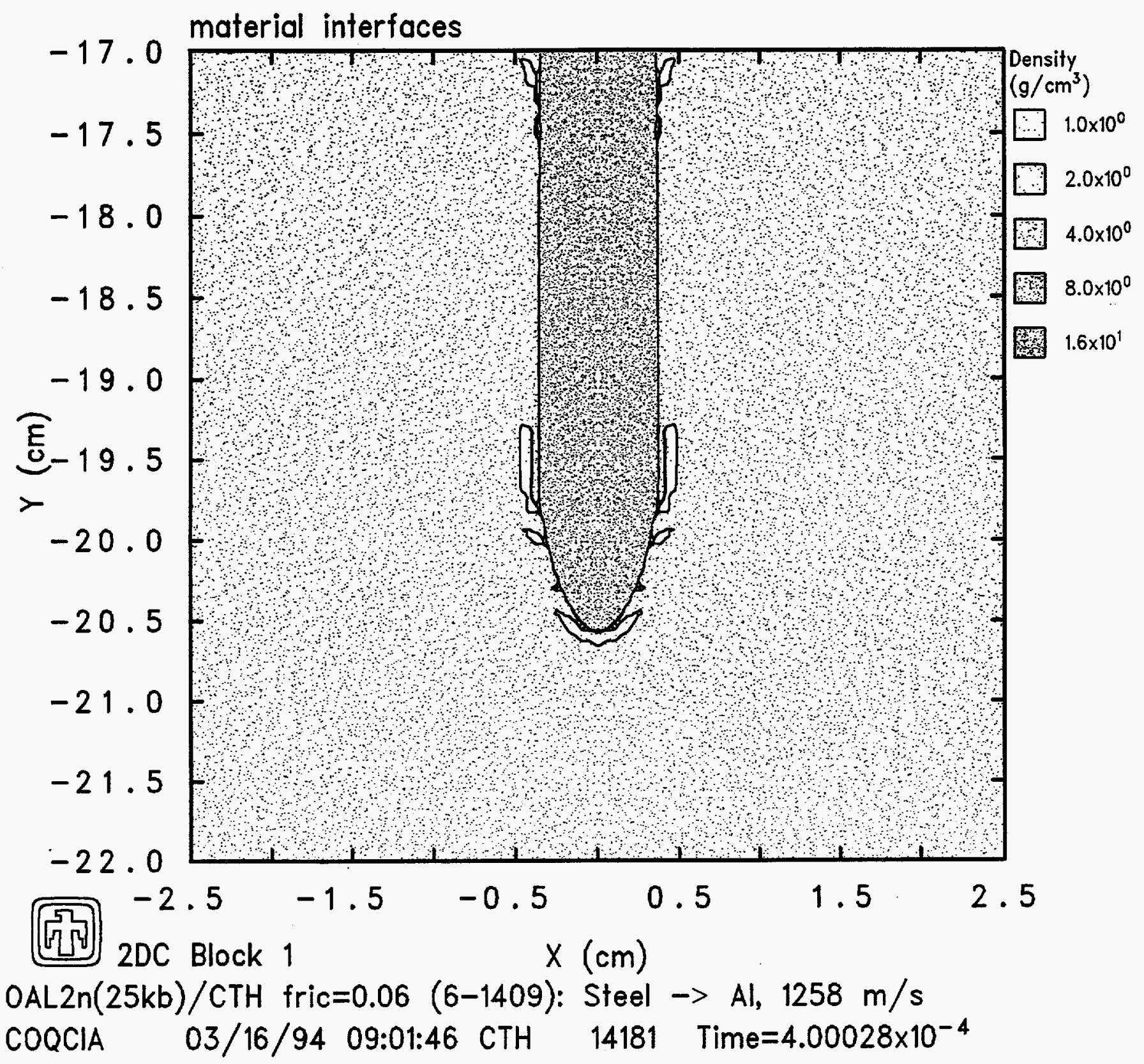

Figure 2.3.2. Predicted Final Configuration for Ogival-Nosed Rod Penetrating 7075-T651 Aluminum Targets at $1258 \mathrm{~m} / \mathrm{s}$ Impact Velocity 

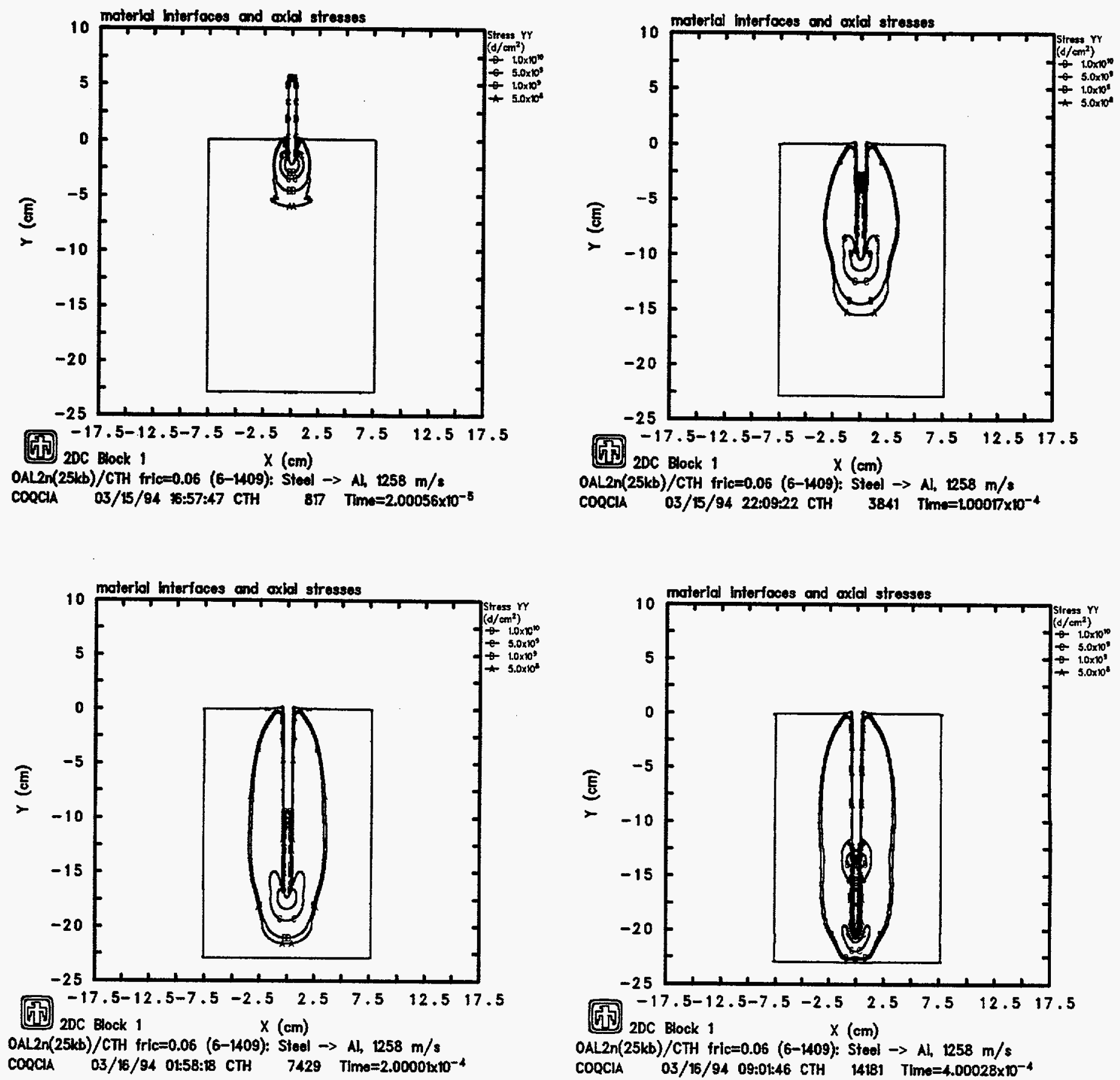

Figure 2.3.3. Axial Stress Contours Predicted by CTH during Penetration for $1258 \mathrm{~m} / \mathrm{s}$ Impact Velocity (A: 0.5kbar, B: 1kbar, C: 5kbar, D: 10kbar) - Ogival-Nosed Rod Penetrating 7075-T651 Aluminum Target 
steady-state value of $\sim 4 \times 10^{6} \mathrm{~m} / \mathrm{s}^{2}\left(\sim 4 \times 10^{5} \mathrm{~g}\right.$ 's) after about four noselengths of penetration. For the impact velocity of $372 \mathrm{~m} / \mathrm{s}$ the penetrator stopped before reaching that steady state level.

The importance and necessity of the boundary layer algorithm [2] in CTH was demonstrated by rerunning one of the calculations without the new model. Calculational results for the $1258 \mathrm{~m} / \mathrm{s}$ impact velocity without the boundary layer algorithm predict less than half the penetration observed in the corresponding experiment. This result highlights the difficulty that an Eulerian code such as CTH can have in correctly predicting penetration of softer targets by nearly-rigid penetrators. The difficulty is due to the effect of materials mixing within cells along the penetrator-target interface. The new CTH boundary-layer algorithm used for the present calculations eliminates the artificial erosion of projectile material in mixed-material cells and allows much more accurate simulation of sliding solid surfaces. 

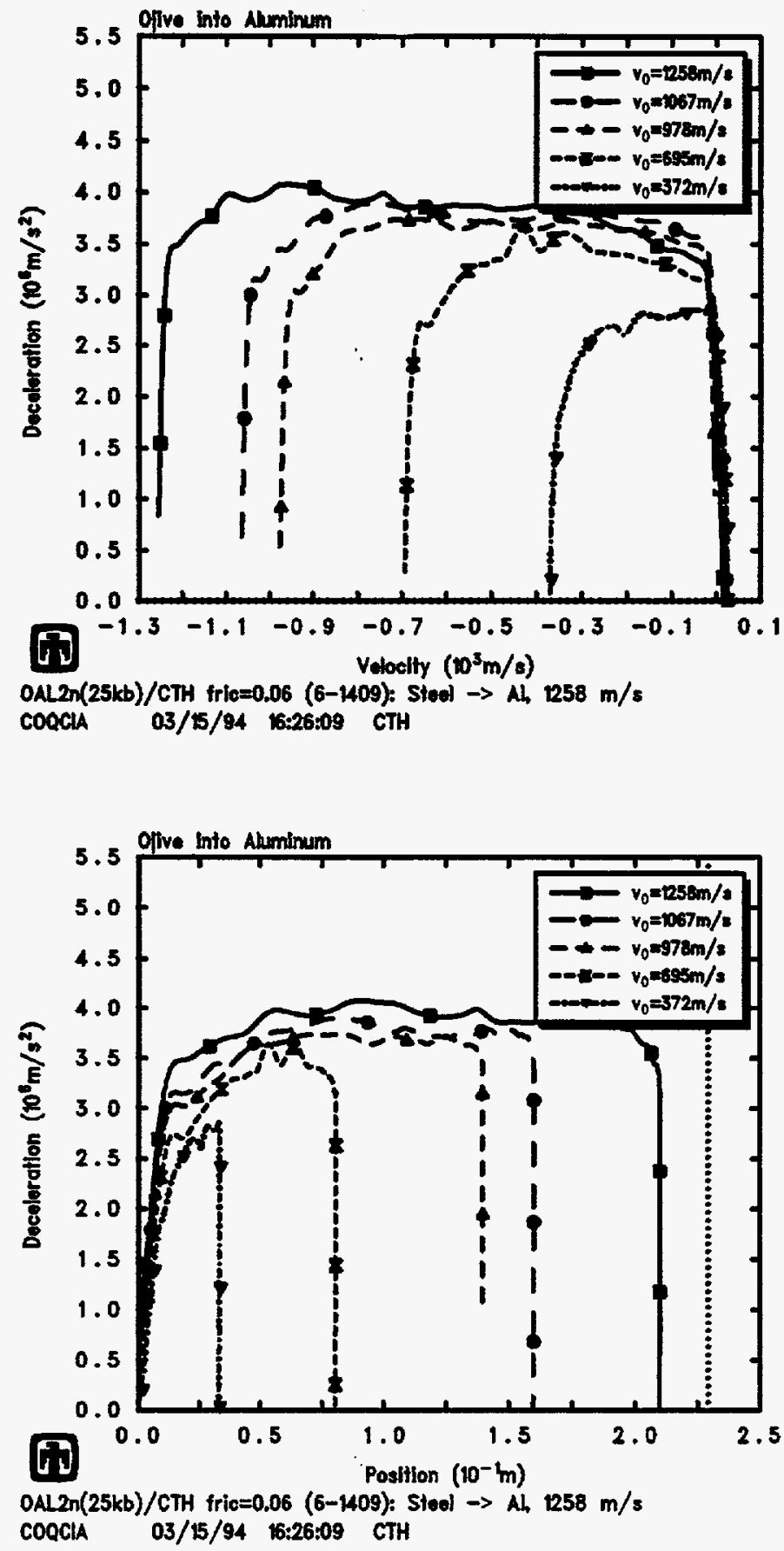

Figure 2.3.4. Rigid-Body Decelerations Predicted by CTH for Various Impact Velocities - Ogival-Nosed Rods Penetrating 7075-T651 Aluminum Targets 


\section{Penetration of Aluminum Targets by Hemispherical- Nosed Steel Rods}

\subsection{Experiment Description}

A second series of metal penetration experiments was conducted by Forrestal, Brar and Luk [5] using hemispherical-nosed, high-stength steel projectiles and 6061-T651 aluminum targets.

The projectile geometry is shown in Figure 3.1.1. The projectiles in these tests had a diameter of $0.711 \mathrm{~cm}$ and body length of $7.112 \mathrm{~cm}$. Note that overall projectile length was somewhat smaller than the ogival-nosed rods discussed in Section 2, due to the blunter hemispherical geometry of the nose. Projectiles were T-200 maraging steel with a density $\rho_{p}$ of $8.02 \mathrm{gm} / \mathrm{cc}$ and a nominal yield stress of $1.72 \mathrm{GPa}$. The range of impact velocities is indicated in Table 3.1.1. Impact was normal to within $3^{\circ}$.

Table 3.1.1. Data Summary - Hemispherical-Nosed Rods and 6061-T651 Aluminum Target Tests

\begin{tabular}{|c|c|c|c|c|c|c|}
\hline $\begin{array}{c}\text { Shot } \\
\text { number }\end{array}$ & $\begin{array}{l}\text { Mass } \\
(\mathrm{gm})\end{array}$ & $\begin{array}{c}V_{0} \\
(\mathrm{~m} / \mathrm{s})\end{array}$ & $\begin{array}{c}\alpha \dagger \\
\text { (degrees) }\end{array}$ & $\begin{array}{c}\beta \dagger \\
\text { (degrees) }\end{array}$ & $\begin{array}{c}P \dot{+} \\
(\mathrm{cm})\end{array}$ & $\begin{array}{l}\text { Target length } \\
(\mathrm{cm})\end{array}$ \\
\hline 2037 & 23.36 & 359 & 0.0 & 1.2 & 2.1 & 9.0 \\
\hline 1961 & 23.34 & 430 & - & 0.2 & 3.2 & 8.9 \\
\hline 1960 & 23.34 & 490 & - & 0.7 & 4.0 & 8.2 \\
\hline 1916 & 23.43 & 519 & 2.0 & 2.8 & 4.1 & 11.4 \\
\hline 1914 & 23.40 & 673 & 0.7 & 1.0 & 7.3 & 17.8 \\
\hline 1915 & 23.44 & 792 & 2.6 & 1.8 & 8.5 & 17.8 \\
\hline 2059 & 23.32 & 959 & 1.0 & 0.5 & 10.9 & 19.8 \\
\hline 1912 & 23.32 & 1009 & 1.0 & 0.2 & 12.9 & 21.6 \\
\hline
\end{tabular}

The targets were cut from $15.2 \mathrm{~cm}$-diameter bars, where the target length for each test is given in Table 3.1.1. In addition, axial and transverse specimens for this bar stock were machined for large-strain compression tests. Four specimens were tested at a strain rate of $10^{-2} / \mathrm{s}$, and Figure 3.1.2 shows the compression stress-strain test data, along with a power law fit to the data [5].

Post-test penetration depths were measured from in-material radiographs, with results summarized in Table 3.1.1. 


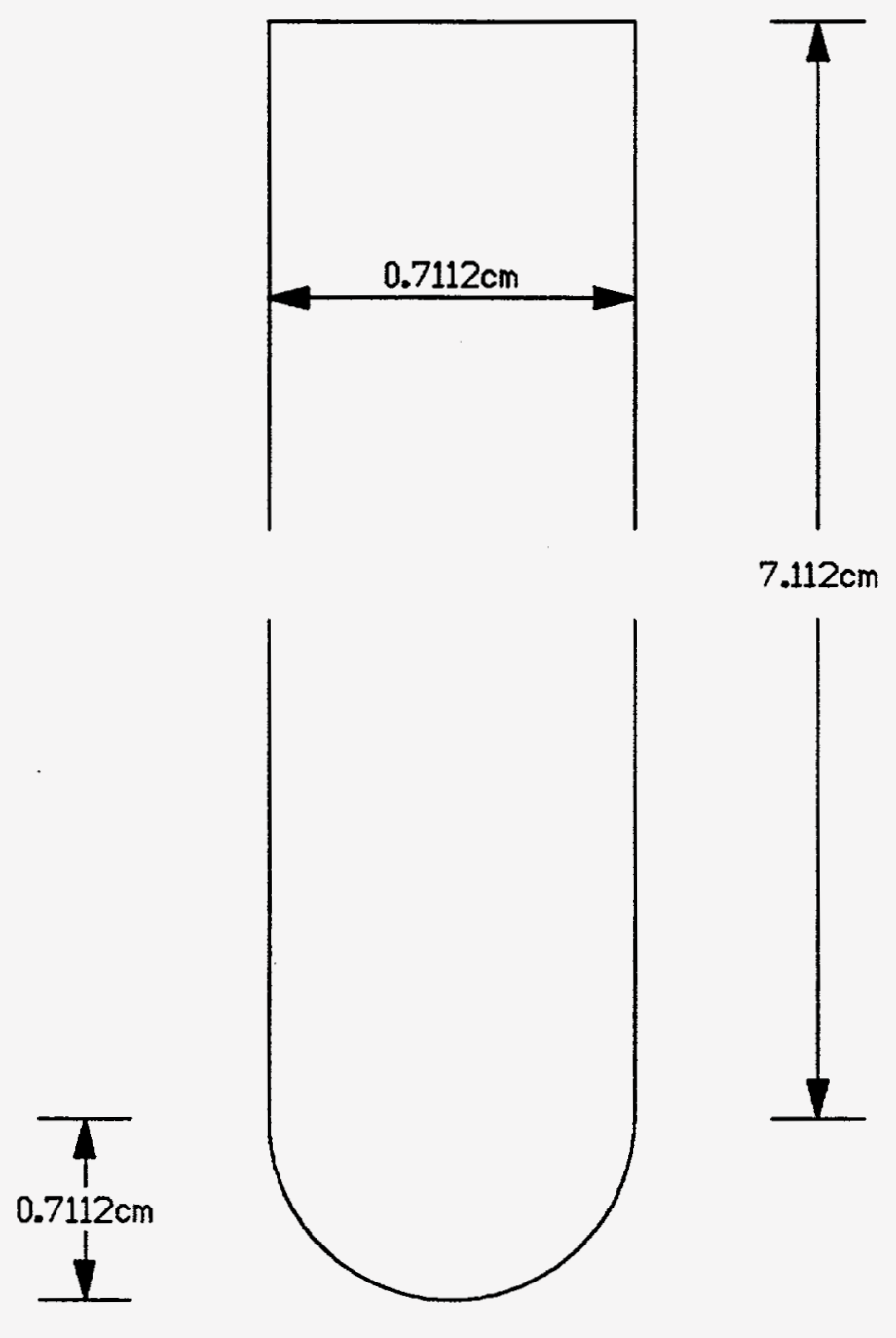

Figure 3.1.1. Projectile Geometry - Hemispherical-Nosed Rod for 6061-T651 Aluminum Target Tests 


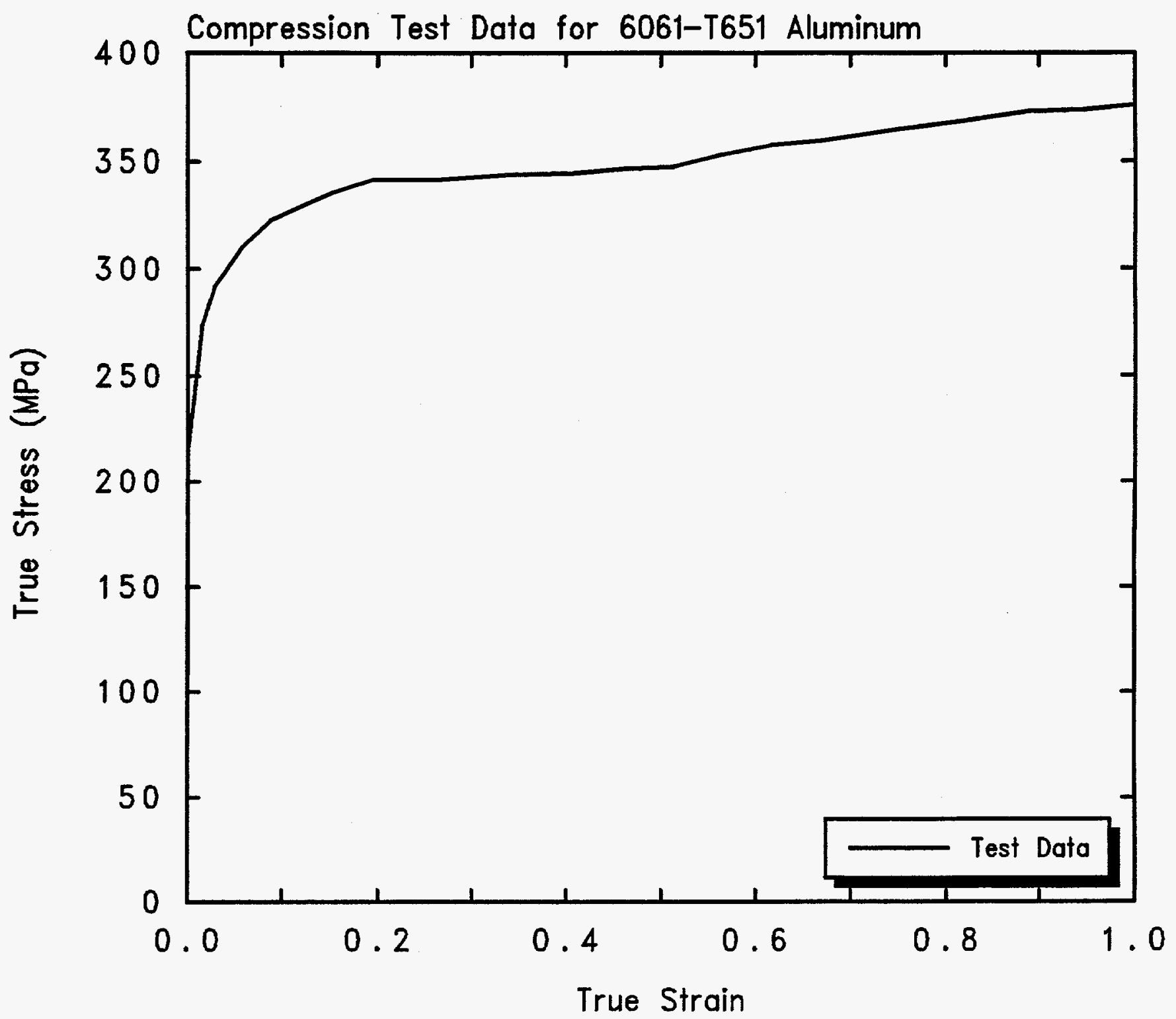

Figure 3.1.2. Stress-Strain Data for the 6061-T651 Target Material 


\subsection{CTH Model Input}

The CTH calculations were performed using 2D cylindrical coordinates and Figure 3.2.1 shows the initial configuration for the calculations.

Most of the calculations were performed with a basecase zoning of $75 \times 750$ cells. The $x$-direction mesh was the same as used in the calculations for the ogival-nosed rods, as discussed in Section 2.2. The slightly smaller rod length and target thickness, however, allowed a small reduction in the extent of the $y$ mesh, so that in the $y$-direction the mesh was started at $y=-22 \mathrm{~cm}$. Thus, a subgrid of square cells again covered the penetration region, with the cell size being $0.04 \mathrm{~cm}$ in both the $\mathrm{x}$ - and $\mathrm{y}$-directions.

Table 3.2.1. Material Properties Used in CTH Analyses for Hemispherical-Nosed Rods Penetrating 6061-T651 Aluminum Targets

$\begin{array}{lcc}\text { Property } & \begin{array}{c}\text { Penetrator } \\ \text { (Steel) }\end{array} & \begin{array}{c}\text { Target } \\ \text { (Aluminum) }\end{array} \\ & & \\ \text { Density, } \rho\left(\mathrm{gm} / \mathrm{cm}^{3}\right) & 8.02 & 2.70 \\ \text { Sound speed, } C_{S}(\mathrm{~cm} / \mathrm{s}) & 4.61 \times 10^{5} & 5.38 \times 10^{5} \\ U_{s}-U_{p} \text { slope, } S & 1.73 & 1.337 \\ \text { Gruneisen coefficient, } \Gamma & 1.67 & 2.100 \\ \text { Specific heat, } C_{V}(\mathrm{erg} / \mathrm{gm}-\mathrm{eV}) & 5.34 \times 10^{10} & 1.02 \times 10^{11} \\ & & \\ \text { Poisson's ratio, } \nu & 0.3 & 0.33 \\ \text { Yield stress, } Y\left(\text { dynes } / \mathrm{cm}^{2}\right) & 17.2 \times 10^{9} & \\ \text { Johnson-Cook model constants } & & \\ A\left(\text { dynes } / \mathrm{cm}^{2}\right) & & 2.76 \times 10^{9} \\ B\left(\text { dynes } / \mathrm{cm}^{2}\right) & & 0.92 \times 10^{9} \\ C\left(\text { dynes } / \mathrm{cm}^{2}\right) & & 0 \\ n & & 0.2591 \\ T_{M}(\mathrm{eV}) & & 0.0792 \\ & & \\ P_{F R A C}\left(\text { dynes } / \mathrm{cm}^{2}\right) & -35 \times 10^{9} & -5 \times 10^{9}\end{array}$

The various material properties used in the CTH calculations are given in Table 3.2.1. Both the penetrator and the target were modelled with an analytic Mie-Gruneisen equation of state. The penetrator was modelled as an elastic-perfectly plastic material and the density and yield strength of the steel were increased to account for boundary layer effects (see Section 2.2) . Both the boundary layer thickness, $w_{b l}$, and the slip layer thickness, $w_{s l}$, were specified to be 0.08 . The aluminum target was modelled using the Johnson-Cook viscoplastic model [7], with material constants based on a fit to the data shown in Figure 3.1.2. 

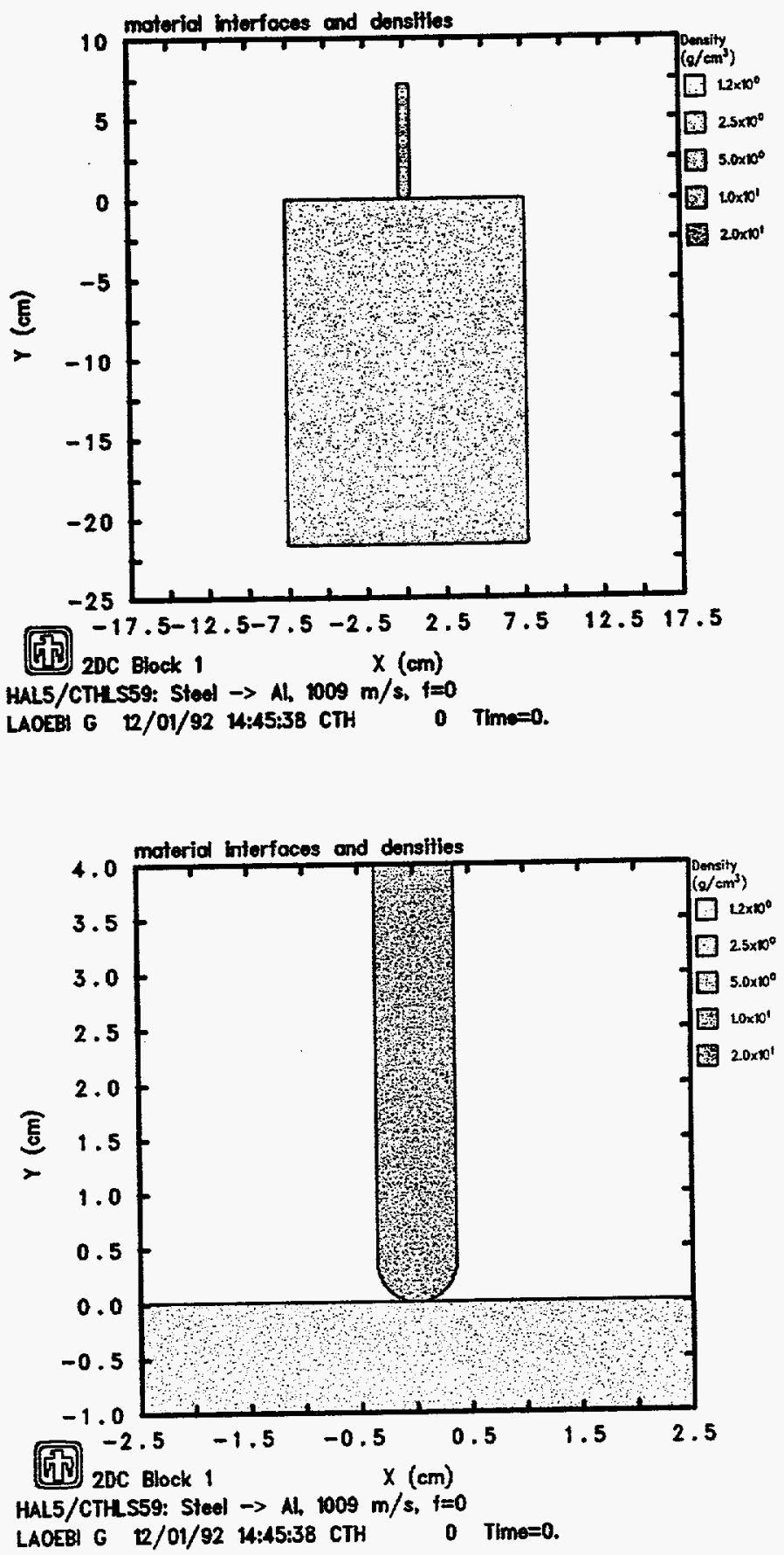

Figure 3.2.1. Initial Configuration for CTH Analyses - Hemispherical-Nosed Rods Penetrating 6061-T651 Aluminum Targets 
The calculations were performed with the nonequilibrium, multi-material temperature and multi-material pressure modelling options, with the high-resolution interface tracker, and without the fragment mover option. Velocity was specified to be convected conserving momentum exactly and discarding any kinetic energy discrepancies. Artificial viscosity was used, with default values for the linear and quadratic coefficients, and the shear artificial viscosity increased to 0.1 . The region around the penetrator and target was modelled as void.

\subsection{Calculational Results}

Calculations were run for eight different values of impact velocity, as indicated in Table 3.1.1. Results of calculations with three different friction coefficients $(0.0,0.03$ and 0.06) are shown in Figure 3.3.1. This plot gives penetration depth as a function of impact velocity. The experimental data [5] are also shown. Both the calculations and the experimental data are represented by the plot symbols, with straight-line segments connecting the results to highlight trends. There is overall good agreement with the data; however, the experimental data generally lie slightly below the calculational results.

Figure 3.3.2 shows the predicted shape of the penetrator and cavity after the penetrator has come to a full stop, for the case of the $1009 \mathrm{~m} / \mathrm{s}$ impact velocity. Again, both calculation and experiment show little or no permanent deformation of the projectile.

Figure 3.3.3 presents the calculated rigid-body decelerations for various impact velocities, as a function of both velocity, in the upper plot, and depth of penetration, in the lower plot. (The rigid-body decelerations plotted in this report are the time derivatives of the mass-weighted average velocity of the penetrator material, smoothed using a bell-shaped function with a $0.05 \mathrm{~ms}$ time constant.)

Since the target material was significantly different for the ogival-nosed and hemispherical-nosed penetration tests, differences in penetration depth were not due to differences in nose shape only. To investigate the influence of nose shape on penetrator performance, the nose geometry was changed to hemispherical in one of the $3 \mathrm{CRH}$ ogival-nosed rod problems, keeping all other factors the same. The result of this calculation is plotted in Figure 3.3.4 and shows about a factor of two decrease in penetration depth for an equal-mass hemispherical-nosed rod relative to the ogival-nosed rod. The rigid-body decelerations for the ogival-nose rod and for the hemispherical-nosed rod are compared in Figure 3.3.5. The factor of $\sim 2$ increase in rigid-body deceleration for the hemisphericalnosed penetrator corresponds to the decrease in penetration depth noted above. 


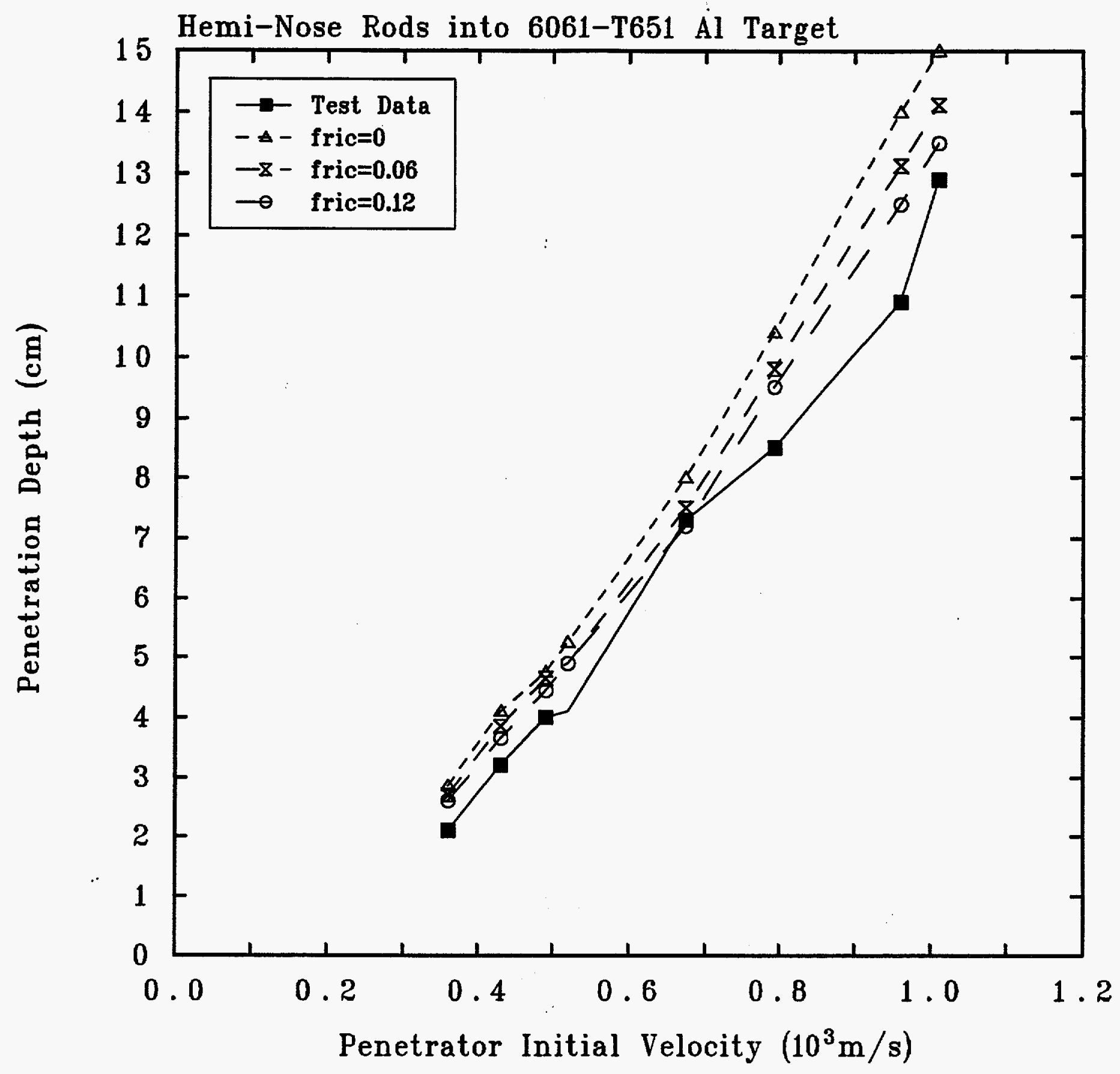

Figure 3.3.1. Penetration Depth Predicted by CTH for Various Impact Velocities and Friction Factors - Hemispherical-Nosed Rods Penetrating 6061-T651 Aluminum Targets 


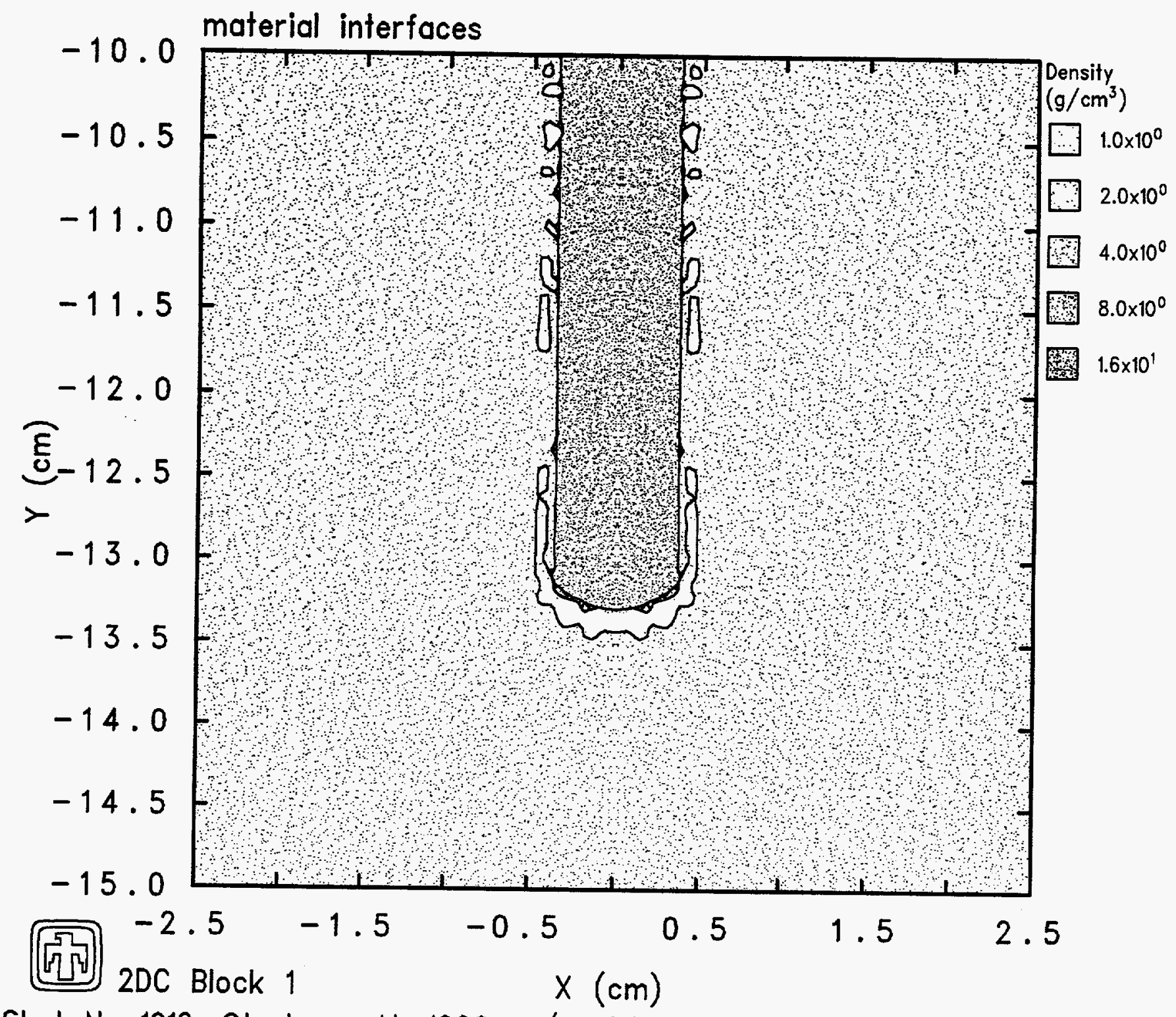

Shot No 1912: Steel $\rightarrow$ Al, $1009 \mathrm{~m} / \mathrm{s}$, fric $=0.12$

DAMAKO 04/03/94 00:53:45 CTH 13854 Time $=4.0003 \times 10^{-4}$

Figure 3.3.2. Final Configuration Predicted by CTH for a Hemispherical-Nosed Rod Penetrating a 6061-T651 Aluminum Target at an Impact Velocity of $1009 \mathrm{~m} / \mathrm{s}$ 

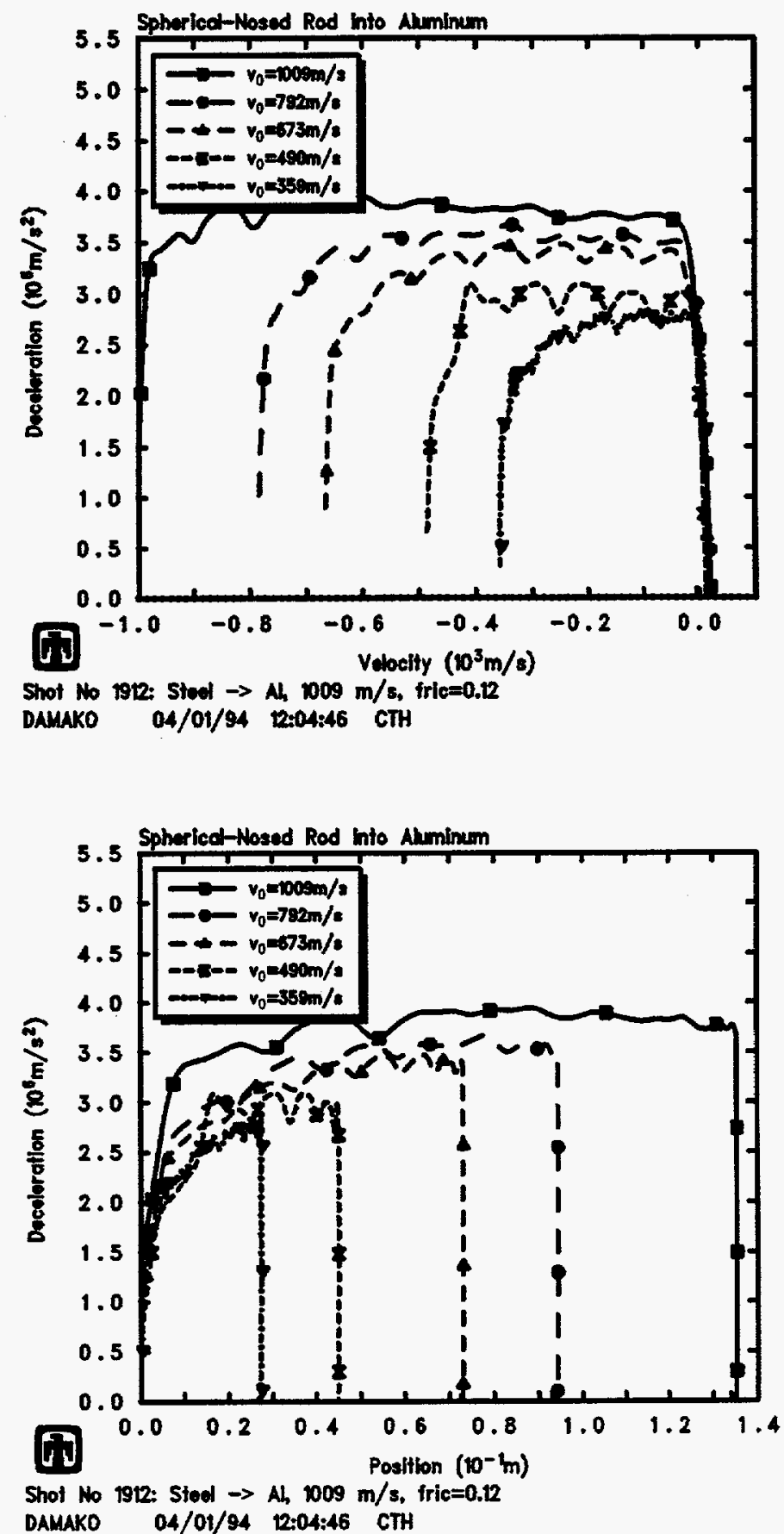

Figure 3.3.3. Rigid-Body Decelerations Predicted by CTH for Various Impact Velocities - Hemispherical-Nosed Rods Penetrating 6061-T651 Aluminum Targets 


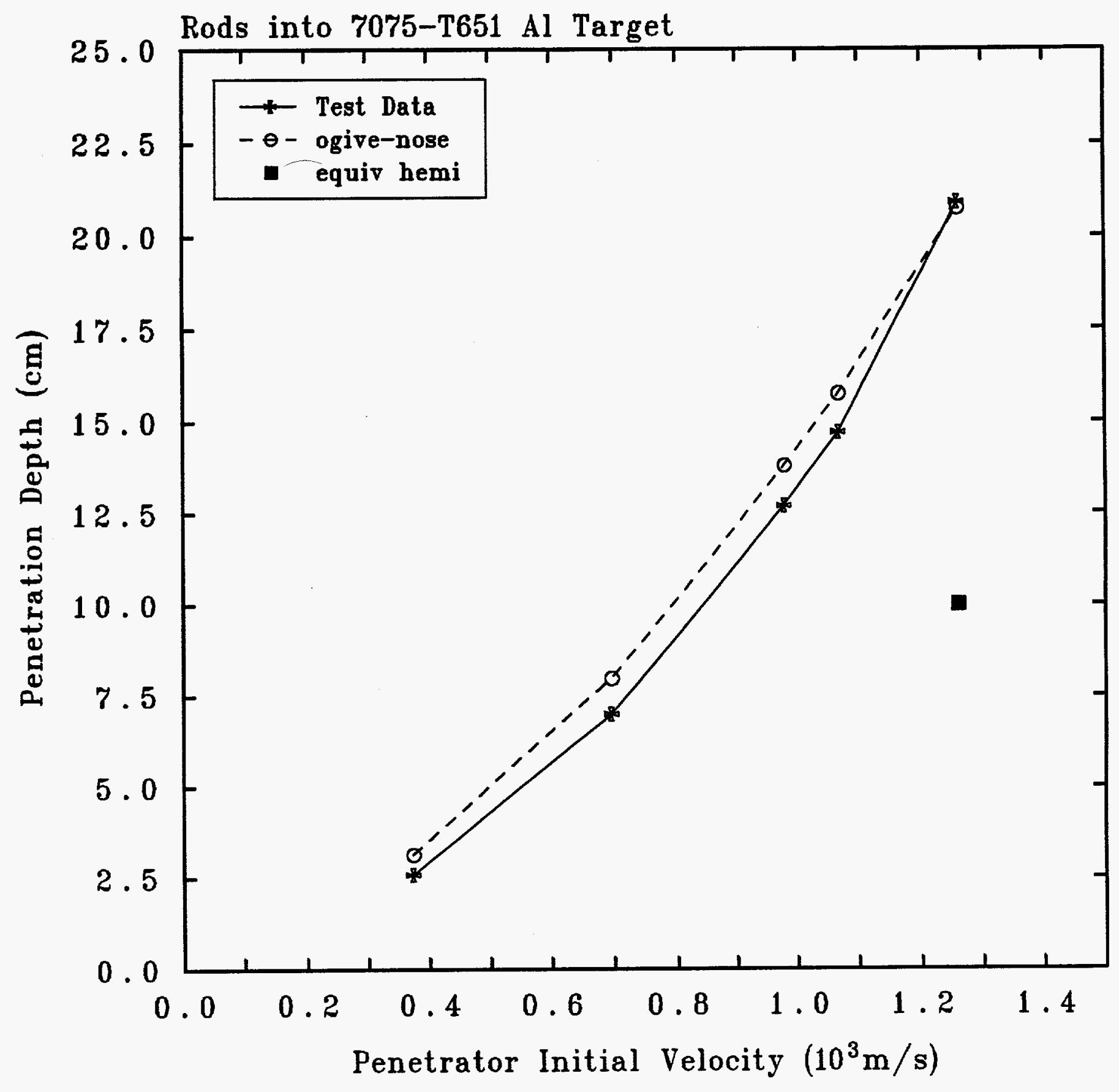

Figure 3.3.4. Penetration Depth Predicted by CTH for Ogival- and

Hemispherical-Nosed Rods of Equal Mass Penetrating 7075-T651

Aluminum Targets 

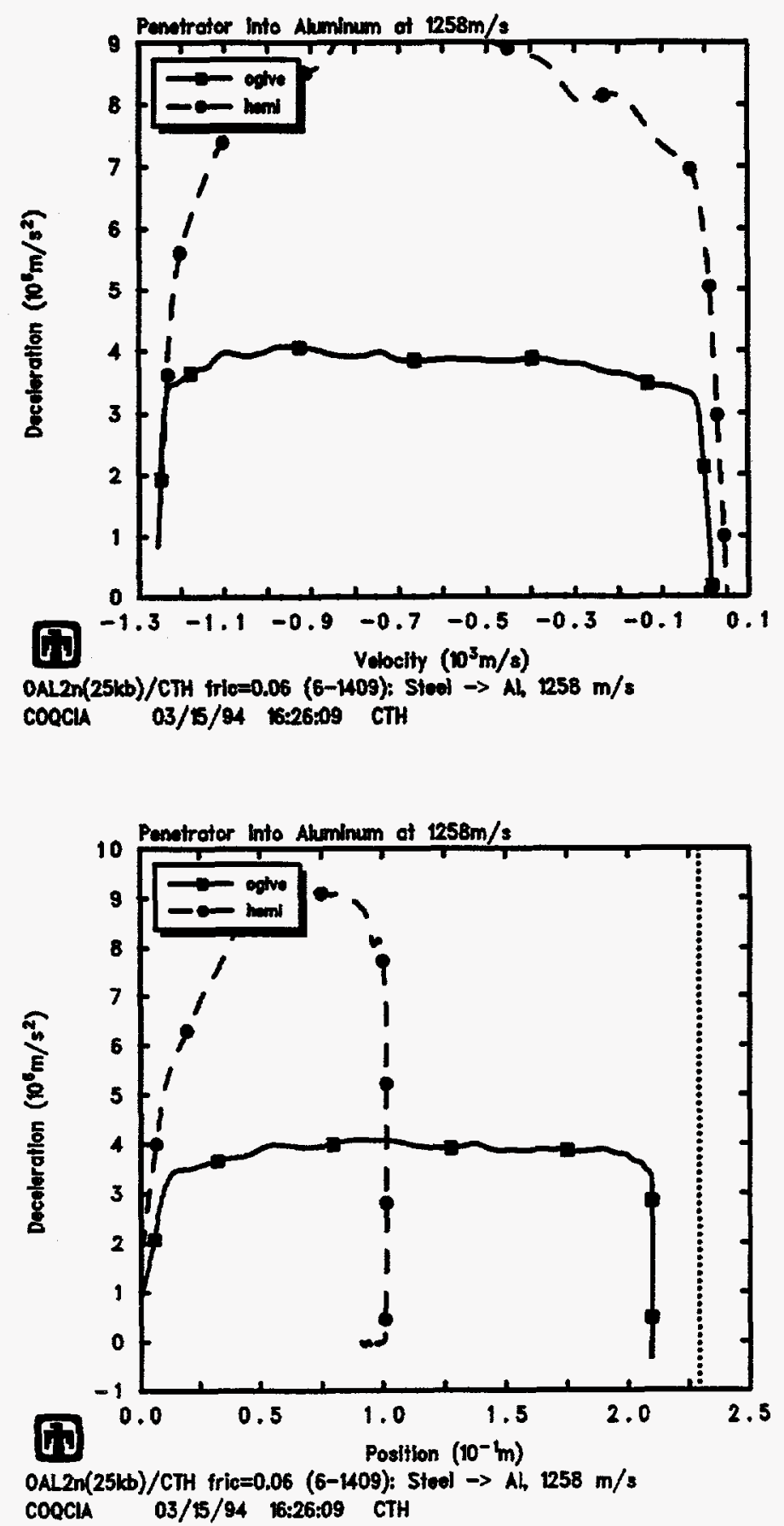

Figure 3.3.5. Rigid-Body Decelerations Predicted by CTH for Ogival- and Hemispherical-Nosed Rods of Equal Mass Penetrating 7075-T651 Aluminum Targets at $1258 \mathrm{~m} / \mathrm{s}$ Impact Velocity 


\section{Penetration of Concrete Targets by Ogival-Nosed Steel Rods}

\subsection{Experiment Description}

Hanchak et al. [6] conducted perforation experiments with $500 \mathrm{gm}, 3 \mathrm{CRH}$ ogival-nosed rods into concrete slabs with $48 \mathrm{MPa}$ and $140 \mathrm{MPa}$ unconfined compressive strengths. The present calculations modelled only the tests in the high-strength material.

The projectile shape is shown in Figure 4.1.1, with a rod diameter of $2.54 \mathrm{~cm}$, a rod length of $10.16 \mathrm{~cm}$, and a nose length of $4.21 \mathrm{~cm}$. Projectiles were machined of T-250 maraging steel with density $\rho_{p}=8.02 \mathrm{gm} / \mathrm{cc}$ and a nominal yield stress of $1.72 \mathrm{MPa}$. The range of impact velocities was between 300 and $1100 \mathrm{~m} / \mathrm{s}$, as given in Table 4.1.1. Impact was normal to within $3^{\circ}$.

Residual velocities given in Table 4.1.1 were measured with flash radiographs, which also showed that the projectiles were not fractured by the targets. Recovered projectiles showed only minor nose erosion.

Table 4.1.1. Data Summary - Ogival-Nosed Rods and 140MPa Concrete Target Tests

$\begin{array}{ccccc}\begin{array}{c}\text { Shot } \\ \text { number }\end{array} & \begin{array}{c}V_{0} \\ (\mathrm{~m} / \mathrm{s})\end{array} & \begin{array}{c}V_{r} \\ (\mathrm{~m} / \mathrm{s})\end{array} & \begin{array}{c}\text { Pitch } \\ \text { (degrees) }\end{array} & \begin{array}{c}\text { Yaw } \\ \text { (degrees) }\end{array} \\ 1-0062 & 376 & 0 & 0 & 2.5 \\ 1-0061 & 382 & 0 & 0 & 2.0 \\ 1-0057 & 443 & 171 & 0 & 0 \\ 1-0066 & 522 & 265 & 1.5 & 1.5 \\ 1-0065 & 587 & 368 & 1.0 & 1.0 \\ 1-0055 & 743 & 544 & 2.0 & 0 \\ 1-0067 & 998 & 842 & 0 & 1.0\end{array}$

The wet density of the high-strength concrete was $2.52 \mathrm{gm} / \mathrm{cc}$, and material property tests were conducted as part of the experimental program [6]. Concrete cylinders $12.7 \mathrm{~cm}$ long and $6.35 \mathrm{~cm}$ in diameter were cast for triaxial material tests. Results of the material property tests on the concrete samples are shown in Figure 4.1.2. Test data for the $48 \mathrm{MPa}$ concrete are included for reference. The tests were conducted in two phases: isotropic compression followed by triaxial shear. The upper plot in Figure 4.1.2 shows results from the isotropic compression phase of the experiments. Three data curves are shown for the $48 \mathrm{MPa}$ concrete, while results from three tests on the $140 \mathrm{MPa}$ concrete were simply bracketed, because the data fell too close to plot separately on this scale. Values of the maximum stress difference (or shear strength) $v s$ pressure are given in the lower plot in 


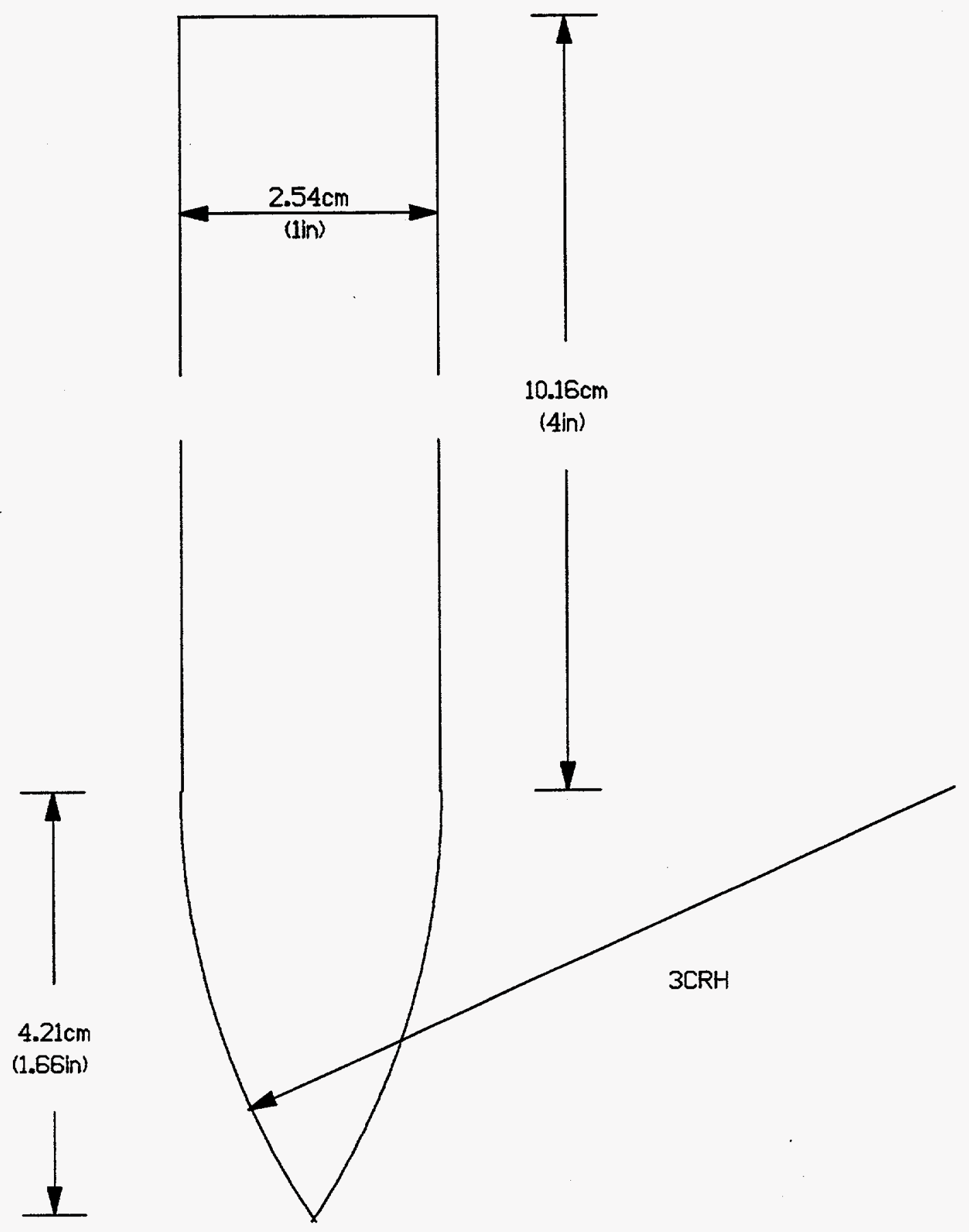

Figure 4.1.1. Projectile Geometry - Ogival-Nosed Rods for $140 \mathrm{MPa}$ Concrete Target Tests 
Figure 4.1.2. Tensile strengths of the two concretes were measured by direct-pull tests, with the maximum unconfined tensile strength for the $140 \mathrm{MPa}$ concrete being $\sim 5 \mathrm{MPa}$.

\subsection{CTH Model Input}

The CTH calculations were performed in 2D cylindrical geometry, and Figure 4.2.1 shows the calculational setup.

Most of the calculations were performed with a basecase zoning of $75 \times 250$ cells. The $x$-direction mesh was started at $x=0$, the axis of symmetry, and extended to a radius of $5.0 \mathrm{~cm}$ (about four times the projectile radius), using 25 uniform cells of $0.20 \mathrm{~cm}$ width. This was followed by 50 more cells of increasing (at $\sim 3 \%$ rate) size in the $x$-direction to an outer radius of $\sim 25 \mathrm{~cm}$, where a transmitting outer boundary condition was imposed. In the $y$-direction, the mesh was started at $y=-35 \mathrm{~cm}$, where $y=0$ was taken as the impact surface and the back surface of the target was at $y=-17.8 \mathrm{~cm}$. Thus, a subgrid of square cells covered the penetration region, with the cell size being $0.20 \mathrm{~cm}$ in both the $x$ - and $y$-directions.

The various material properties used in the CTH calculations for this problem are given in Table 4.2.1. The penetrator and boundary layer were modelled as discussed in Section 2.2. Both the boundary layer thickness, $w_{b l}$, and the slip layer thickness, $w_{s l}$, were specified to be $0.30 \mathrm{~cm}$. The concrete target was modelled using the Johnson-Holmquist ceramic model [8], with material properties listed in Table 4.2.1.

As in the earlier metal penetration problems, the concrete penetration calculations were performed with the nonequilibrium, multi-material temperature and multi-material pressure modelling options, with the high-resolution interface tracker, and without the fragment mover option. Velocity was specified to be convected conserving momentum exactly and discarding any kinetic energy discrepancies. Artificial viscosity was used, with default values for the linear and quadratic coefficients, and the shear artificial viscosity increased to 0.1 . The region around the penetrator and target was modelled as void.

\subsection{Calculational Results}

Calculations were run for six different values of impact velocity $(350,400,500,600$, 800 , and $1000 \mathrm{~m} / \mathrm{s}$ ). While these do not correspond exactly to any of the test conditions given in Table 4.1.1, they bracket the range of impact velocities used in the test series.

Calculated residual velocities for friction coefficients $f$ of 0.01 and 0.10 are shown in Figure 4.3.1 as a function of impact velocity. The experimental data [6] are also shown. Generally, the calculated results and experimental data are in very good agreement. Curiously, there is little difference between calculational results for $f=0.01$ and $f=0.10$.

Figure 4.3.2 illustrates the shape of the penetrator and cavity predicted at four different times during the penetration process for an impact velocity of $1000 \mathrm{~m} / \mathrm{s}$. 

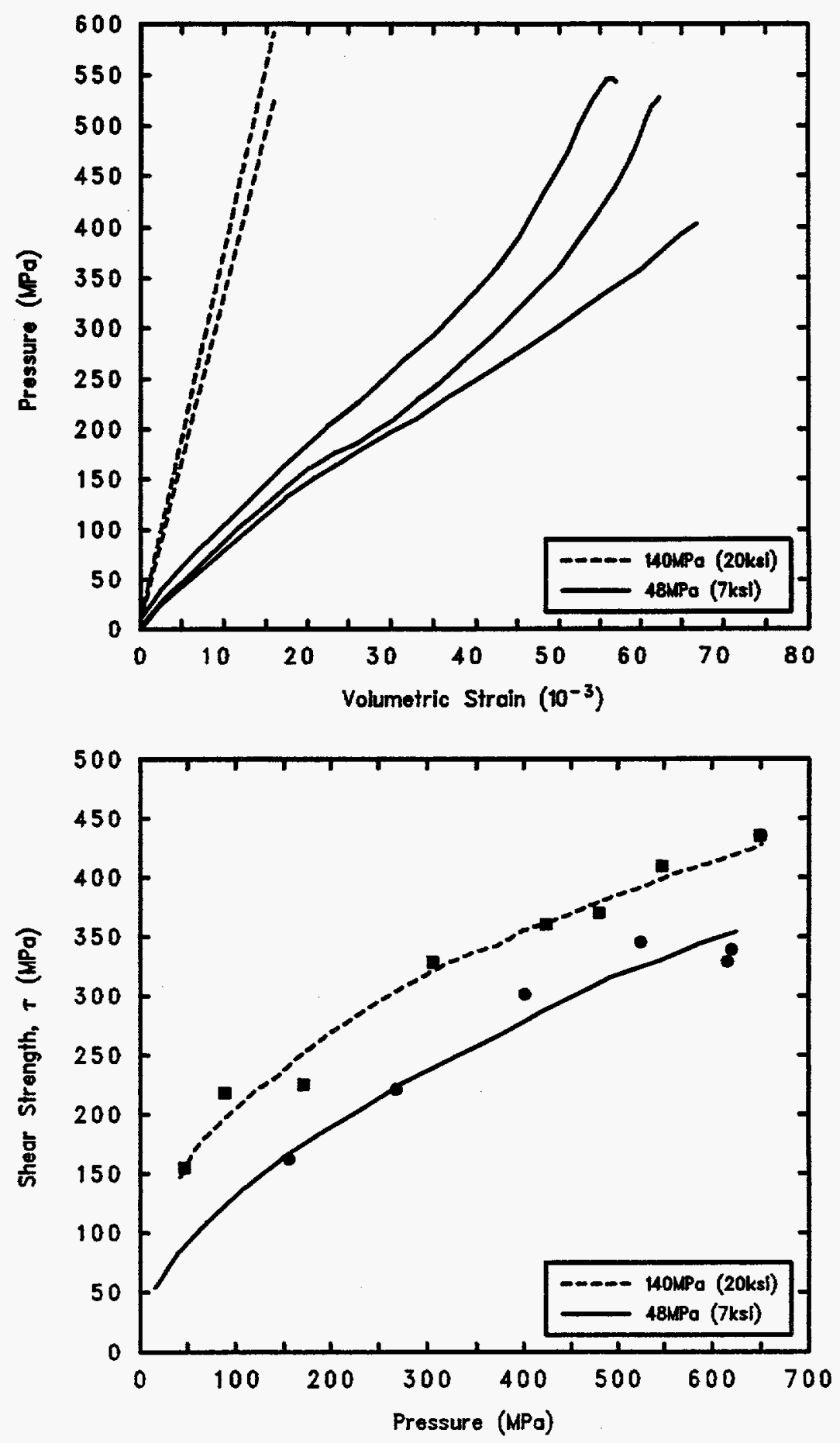

Figure 4.1.2. Materials Property Data for the $48 \mathrm{MPa}$ and $140 \mathrm{MPa}$ Concrete Target Materials 

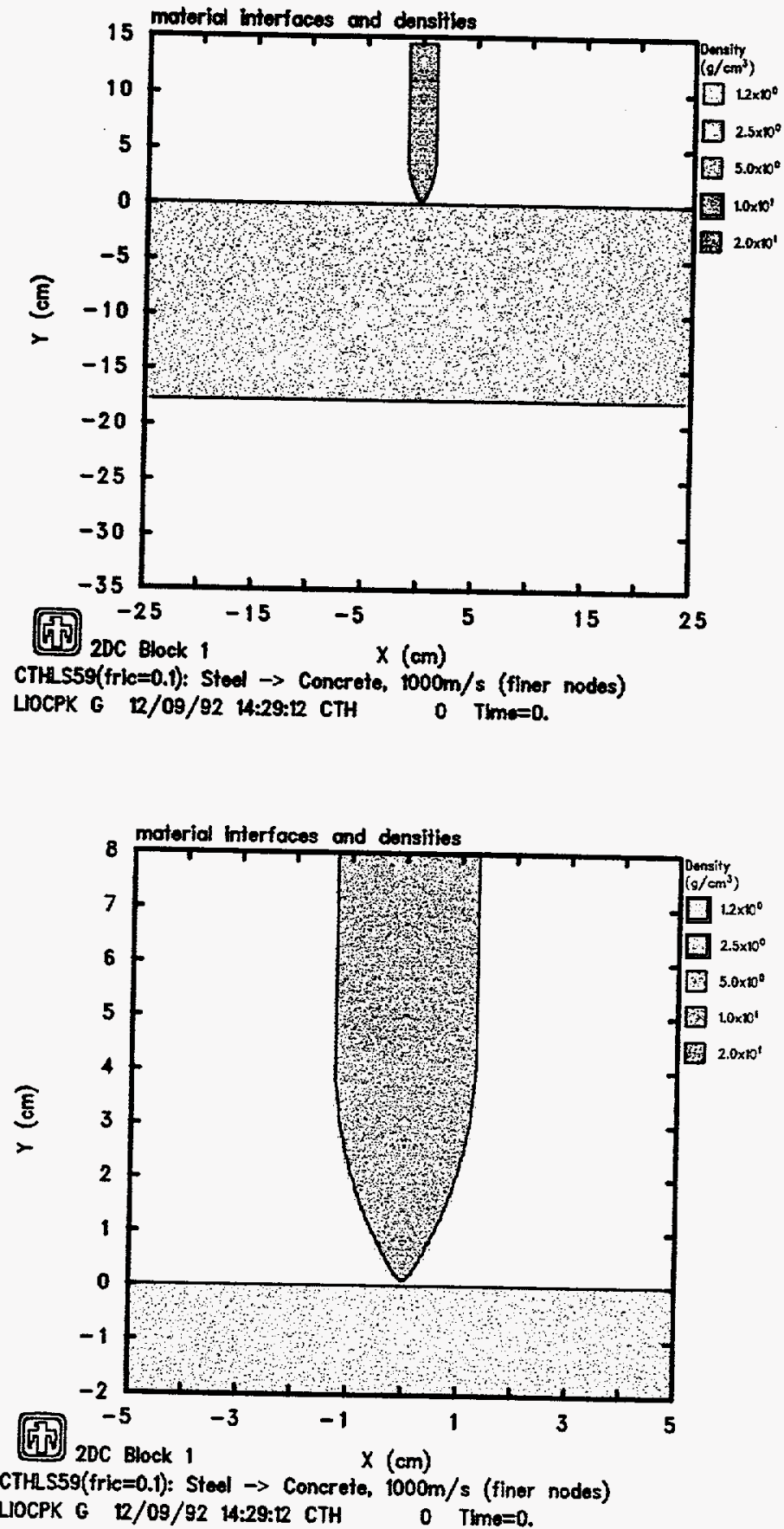

Figure 4.2.1. Initial Configuration for CTH Analyses - Ogival-Nosed Rods Penetrating 140MPa Concrete Targets 
Table 4.2.1. Material Properties Used in CTH Analyses of Ogival-Nosed Rods Penetrating 140MPa Concrete Targets

Property

Density, $\rho\left(\mathrm{gm} / \mathrm{cm}^{3}\right)$

Sound speed, $C_{S}(\mathrm{~cm} / \mathrm{s})$

$U_{s}-U_{p}$ slope, $S$

Gruneisen coefficient, $\Gamma$

Specific heat, $C_{V}$ (erg/gm-eV)

Poisson's ratio, $\nu$

Yield stress, $Y$ (dynes $/ \mathrm{cm}^{2}$ )

Johnson-Holmquist model constants

$T$ (dynes $/ \mathrm{cm}^{2}$ )

$p_{1}\left(\right.$ dynes $\left./ \mathrm{cm}^{2}\right)$

$p_{2}\left(\right.$ dynes $\left./ \mathrm{cm}^{2}\right)$

$Y_{1}\left(\right.$ dynes $\left./ \mathrm{cm}^{2}\right)$

$Y_{2}$ (dynes $\left./ \mathrm{cm}^{2}\right)$

$Y_{3}$ (dynes $\left./ \mathrm{cm}^{2}\right)$

$C_{3}$ (dynes $\left./ \mathrm{cm}^{2}\right)$

$C_{6}\left(\mathrm{dynes} / \mathrm{cm}^{2}\right)$

$\epsilon^{p f *}$

$K_{1}\left(\right.$ dynes $\left./ \mathrm{cm}^{2}\right)$

$K_{2}$ (dynes $\left./ \mathrm{cm}^{2}\right)$

$K_{3}$ (dynes $\left./ \mathrm{cm}^{2}\right)$

$\beta$

$p *\left(\right.$ dynes $\left./ \mathrm{cm}^{2}\right)$

$G$ (dynes $\left./ \mathrm{cm}^{2}\right)$

$P_{\text {FRAC }}$ (dynes $/ \mathrm{cm}^{2}$ )
Penetrator Target

(Steel) (Concrete)

$8.02 \quad 2.52$

$4.610 \times 10^{5}$

1.73

1.67

$5.34 \times 10^{10} \quad 1 \times 10^{11}$

0.3

$17.2 \times 10^{9}$
$-2 \times 10^{8}$

$1 \times 10^{9}$

$7 \times 10^{9}$

$2 \times 10^{9}$

$4.5 \times 10^{9}$

$4.5 \times 10^{9}$

$1 \times 10^{-6}$

0.6

$1 \times 10^{99}$

$4 \times 10^{11}$

0

0

0

0

$1.25 \times 10^{11}$

$\begin{array}{ll}-35 \times 10^{9} & -2 \times 10^{8}\end{array}$ 


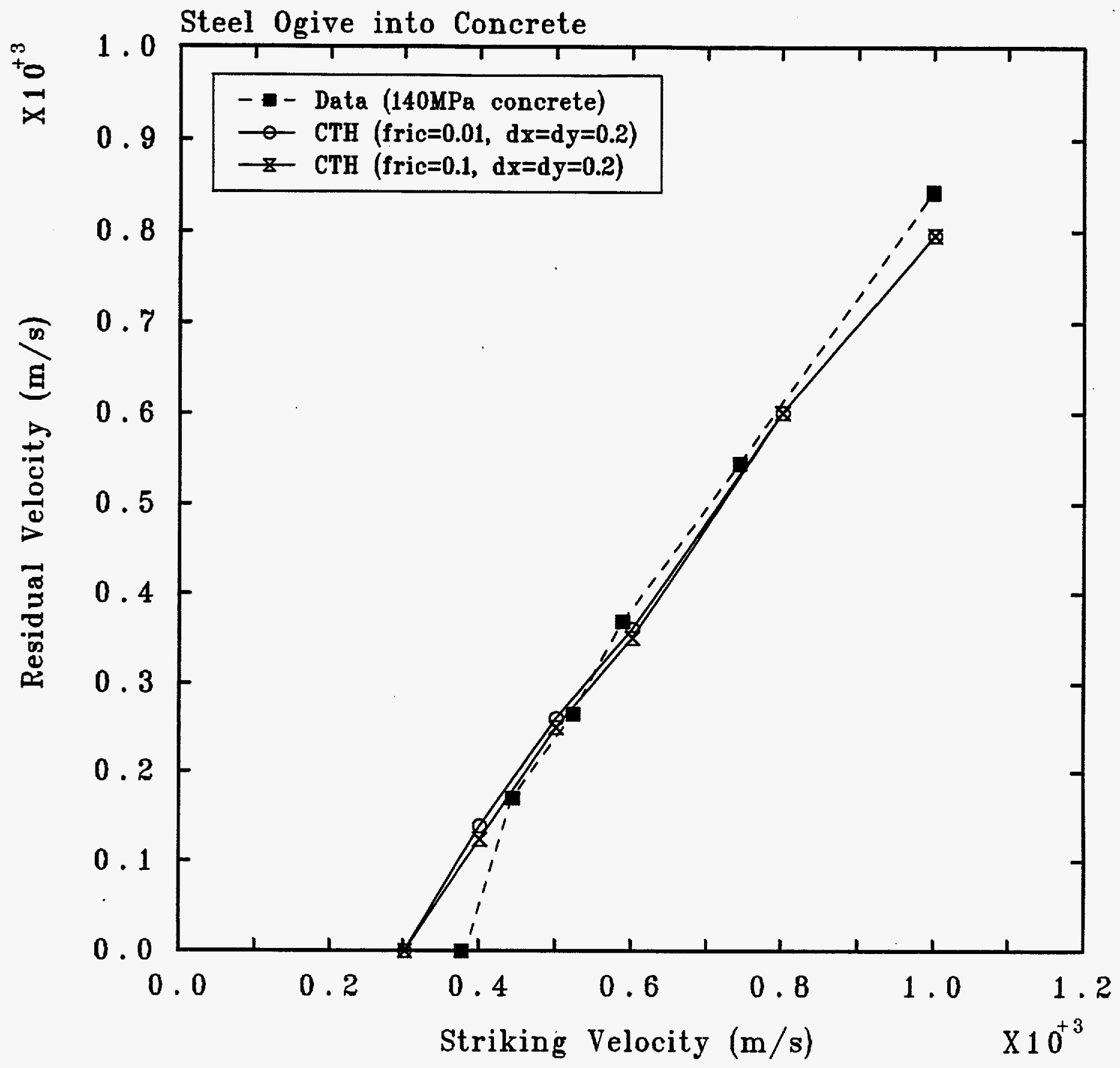

Figure 4.3.1. Residual Velocity Predicted by CTH for Various Impact Velocities and Friction Factors - Ogival-Nosed Rods Penetrating 140MPa Concrete Targets 

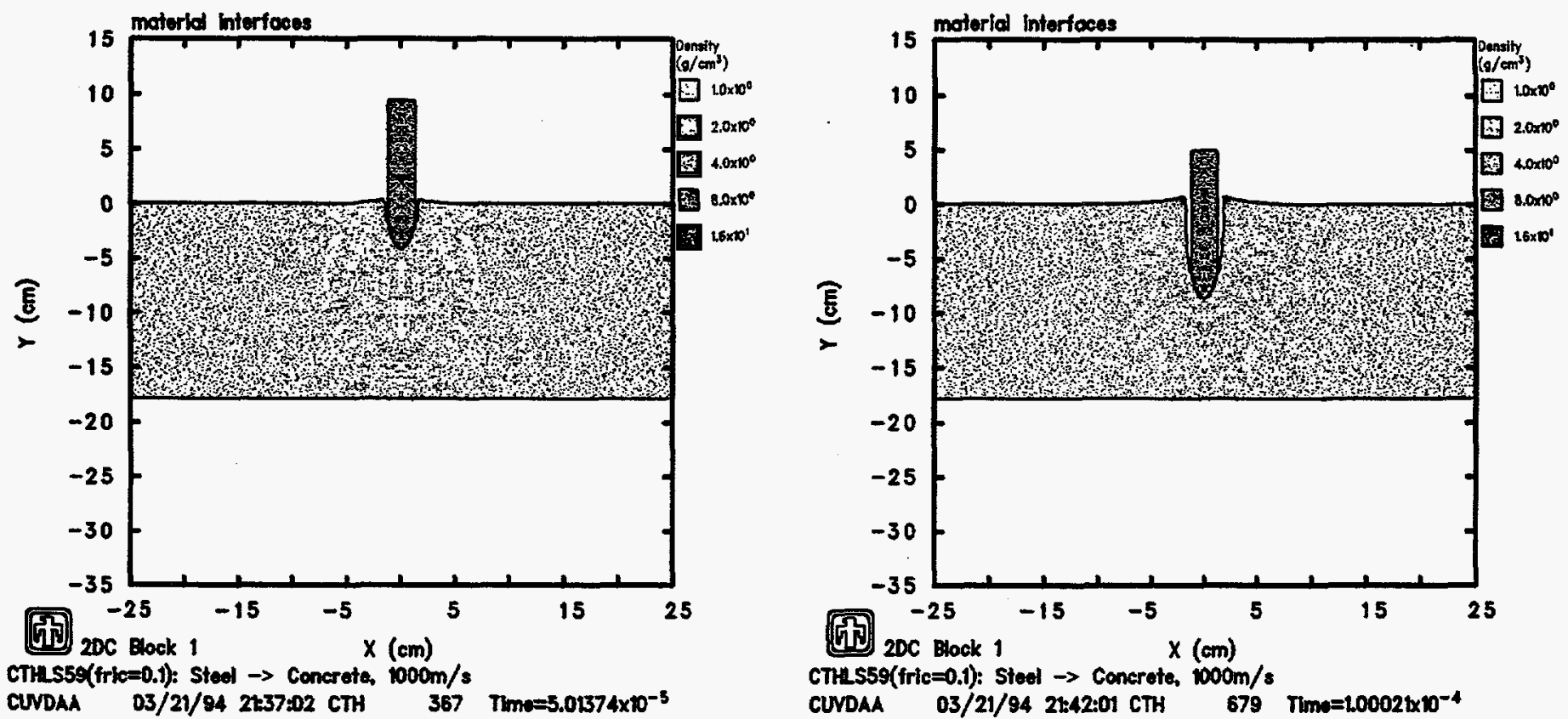

CTILS59(fric $=0.1$ ): Steel $\rightarrow$ Conerete, $1000 \mathrm{~m} / \mathrm{s}$

CUVDAA 03/21/94 2k42:01 CTH $679 \pi \mathrm{mm}=1.00021 \times 10^{-4}$
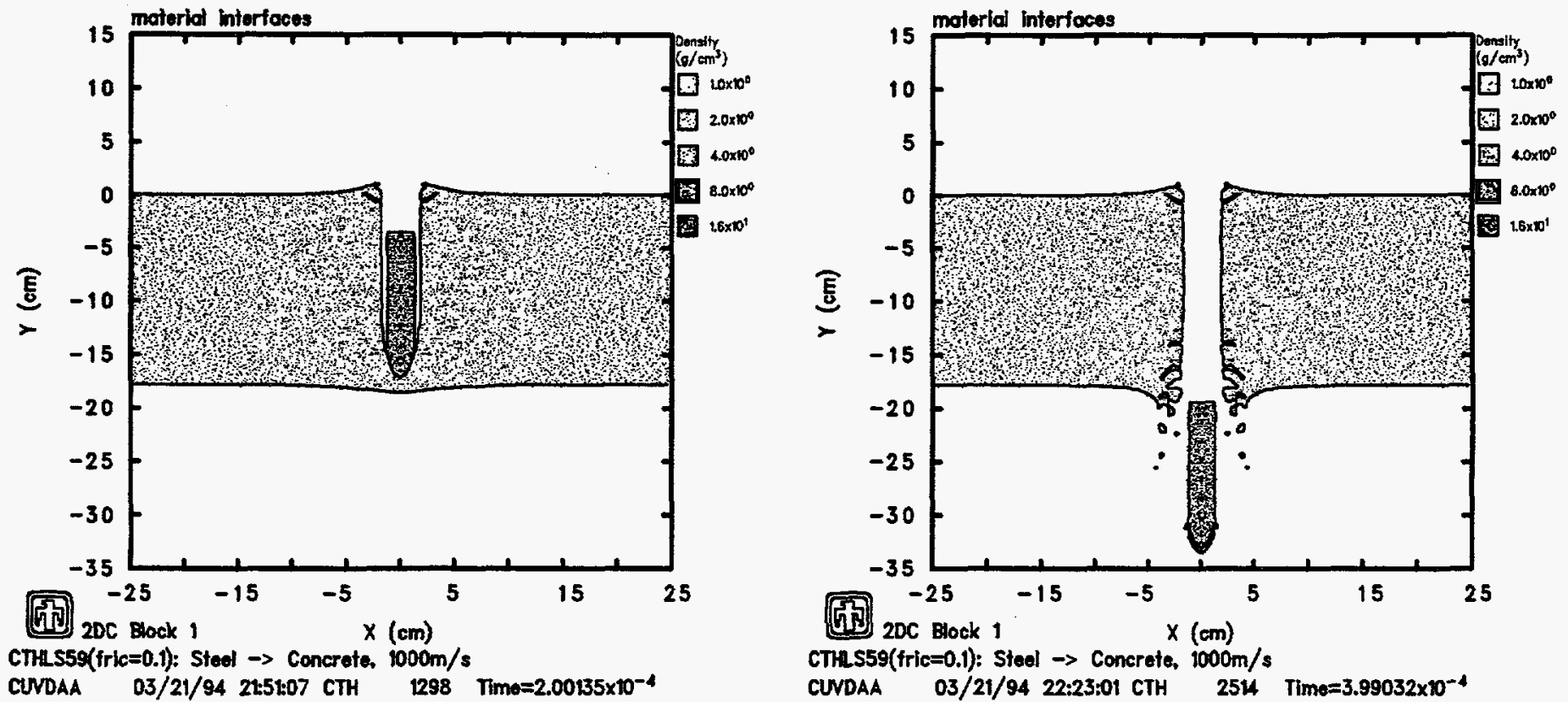

Figure 4.3.2. Penetrator and Target Configurations Predicted by CTH -

Ogival-Nosed Rod Penetrating 140MPa Concrete Target at an Impact Velocity of $1000 \mathrm{~m} / \mathrm{s}$ 
Figure 4.3.3 presents the rigid-body decelerations calculated for the various impact velocities, as a function of both velocity, in the upper plot, and depth of penetration, in the lower plot. (The rigid-body decelerations plotted in this report are the time derivatives of the mass-weighted average velocity of the penetrator material, smoothed using a bell-shaped function with a $0.05 \mathrm{~ms}$ time constant.) For all impact velocities plotted, the decelerations between the initial rise and the final drop all fall on approximately the same deceleration $v s$ velocity curve.

Calculations were done using progressively finer zoning for an impact velocity of $1000 \mathrm{~m} / \mathrm{s}$ with friction coefficient $f=0.10$. In the penetration region, the zoning resolution was progressively refined by factors of 2 in each direction, to $\Delta x=\Delta y=0.10$ and then $\Delta \mathrm{x}=\Delta \mathrm{y}=0.05$, while maintaining $w_{b l}=w_{s l}=1.5 \times(\Delta \mathrm{x}=\Delta \mathrm{y})$. Thus, for $\Delta \mathrm{x}=\Delta \mathrm{y}=0.10$ we set $w_{b l}=w_{s l}=0.15$, and for $\Delta \mathrm{x}=\Delta \mathrm{y}=0.05$ we set $w_{b l}=w_{s l}=0.075$. Results of the calculations are shown in Figure 4.3.4. The residual velocities calculated for this problem converge smoothly to the experimental result as the zoning is progressively refined. Figure 4.3.5 illustrates the corresponding decrease in rigid-body deceleration as the zoning resolution is improved and the associated boundary and slip layer thicknesses are decreased.

A final set of studies was done for an impact velocity of $1000 \mathrm{~m} / \mathrm{s}$ and the basecase zoning, in which a number of the Johnson-Holmquist material parameters used to model the concrete target were varied (see Section 4.2). The results of these sensitivity studies are shown in Figure 4.3.6. The results show little effect on residual velocity of most of the changes made. The biggest effect was seen when the limiting value of material strength (i.e., $Y_{2}$ ) was reduced and, as would be expected, a softer concrete model resulted in a higher predicted residual velocity. 

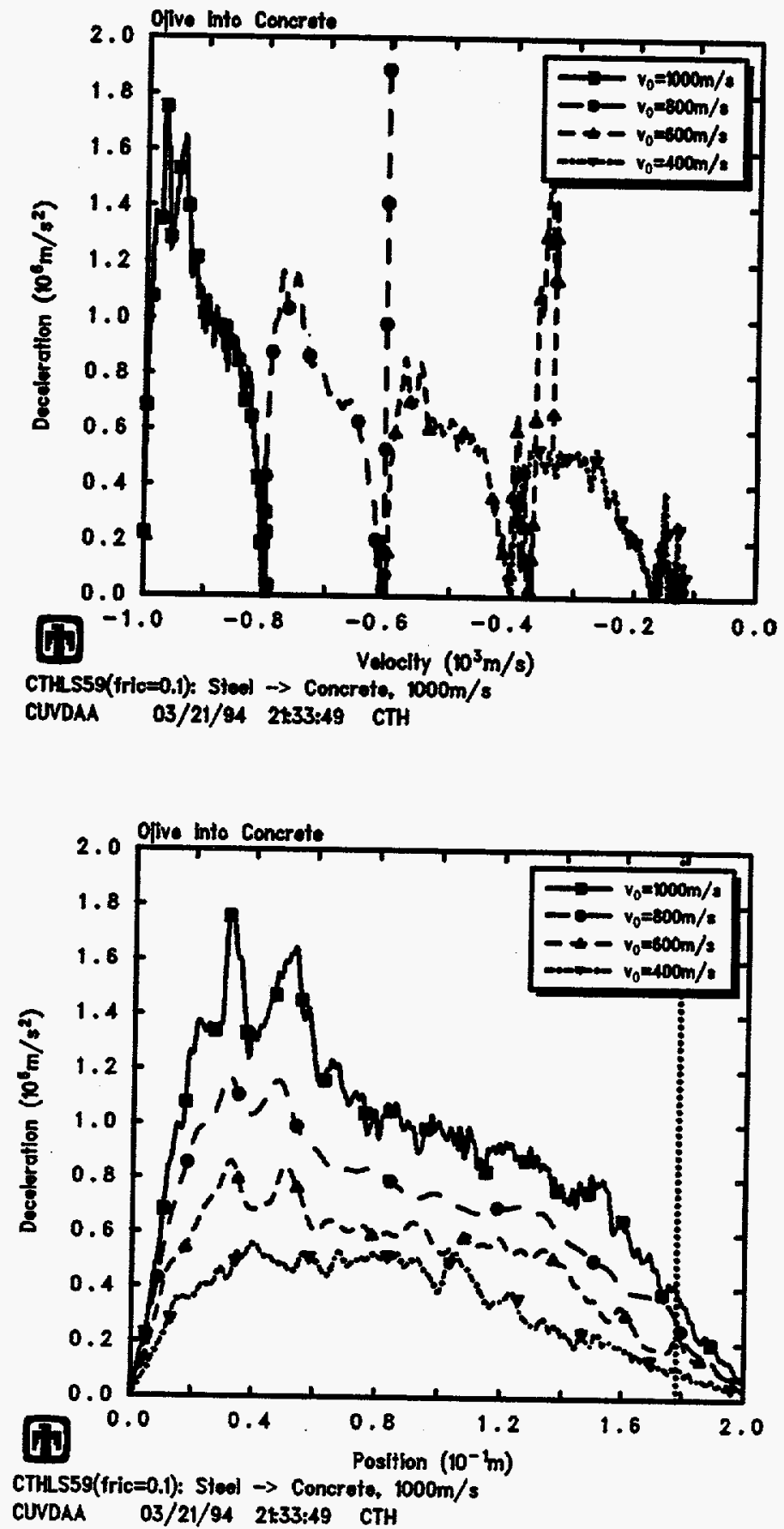

Figure 4.3.3. Rigid-Body Decelerations Predicted by CTH for Various Impact Velocities - Ogival-Nosed Rods Penetrating 140MPa Concrete Targets 


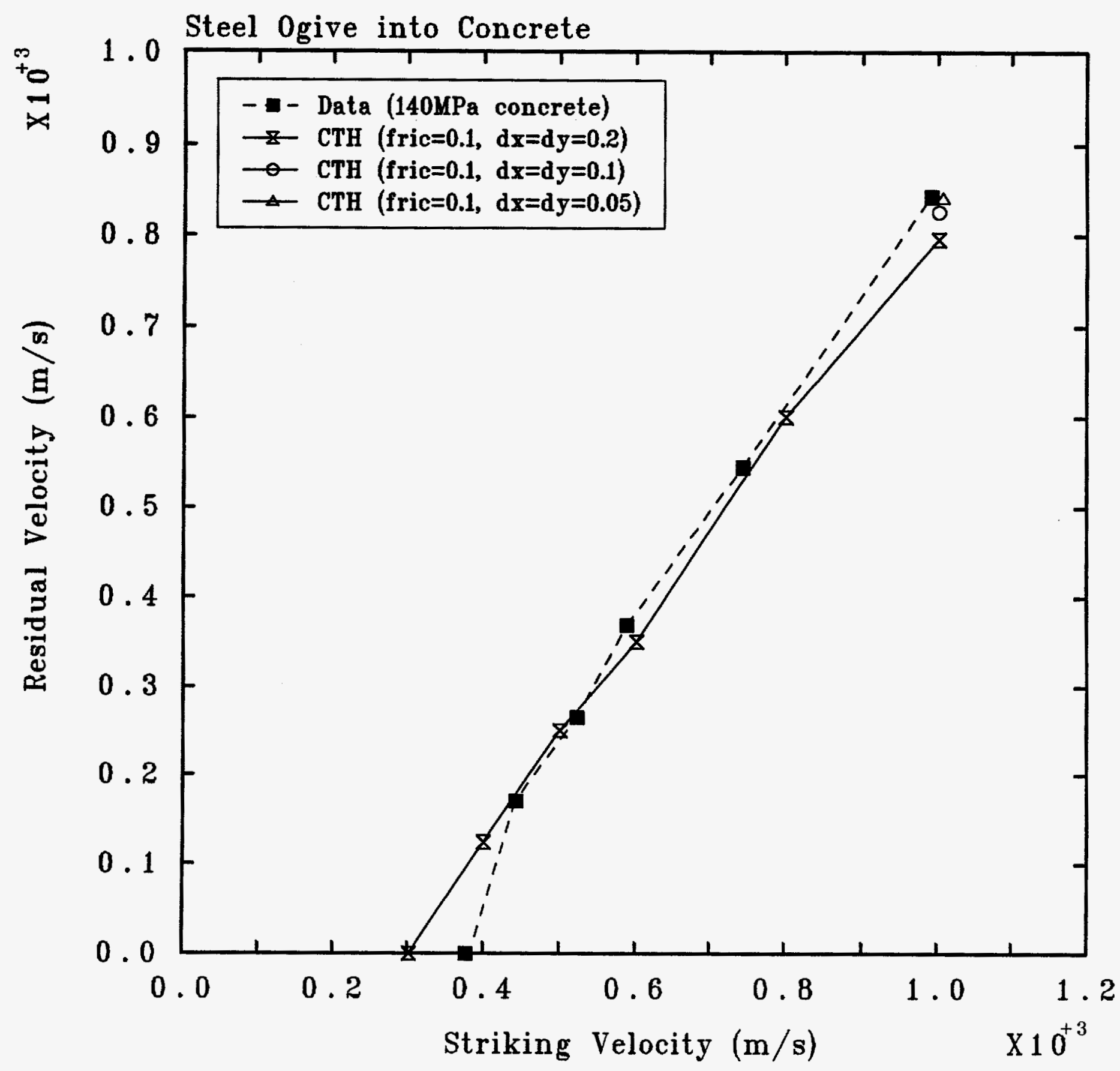

Figure 4.3.4. Residual Velocity Predicted by CTH for Various Impact Velocities and Calculational Zone Sizes - Ogival-Nosed Rods Penetrating 140MPa Concrete Targets 

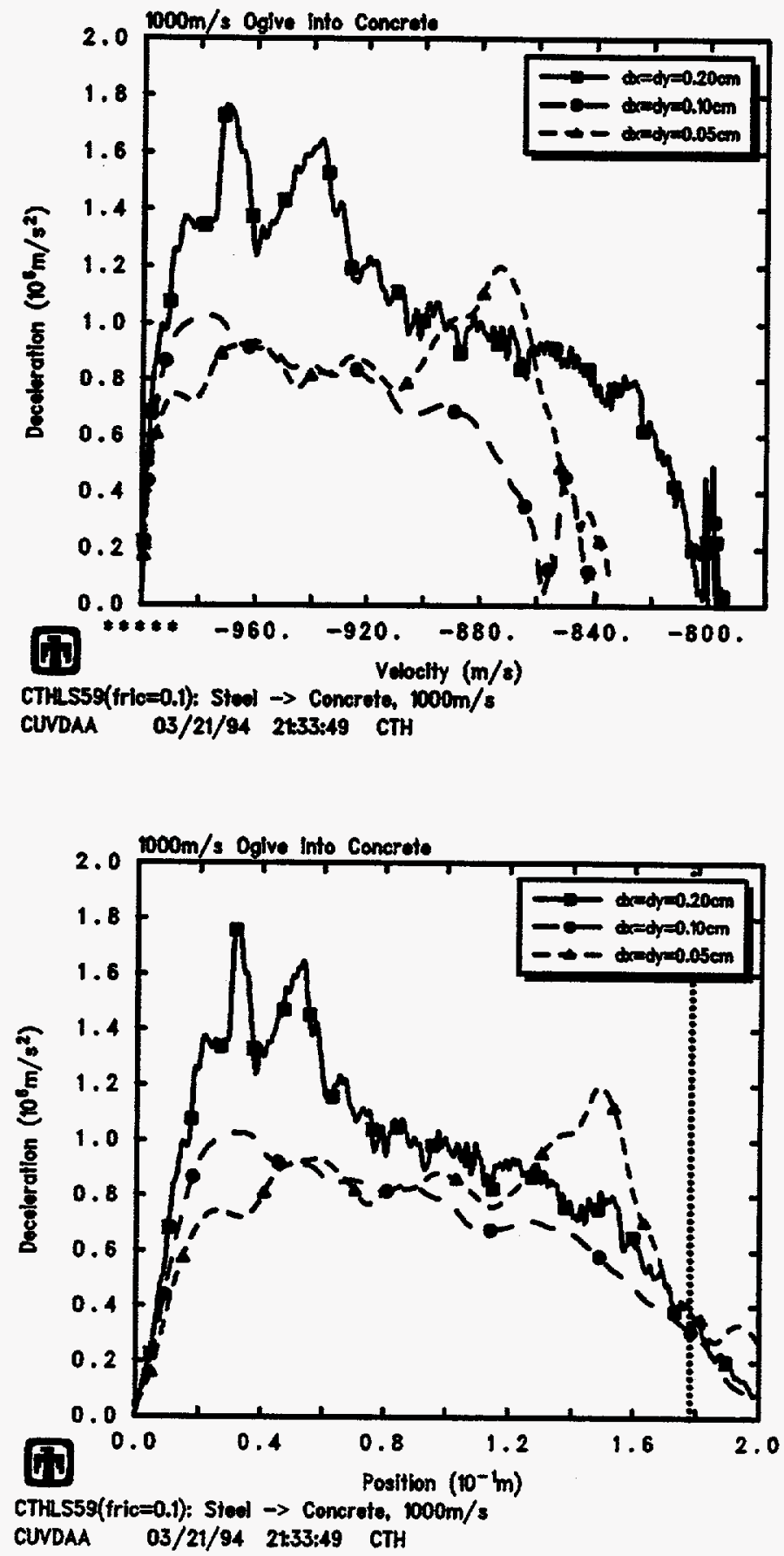

Figure 4.3.5. Rigid-Body Decelerations Predicted by CTH for an Impact Velocity of $1000 \mathrm{~m} / \mathrm{s}$ with Different Zone Sizes - Ogival-Nosed Rods Penetrating $140 \mathrm{MPa}$ Concrete Targets 


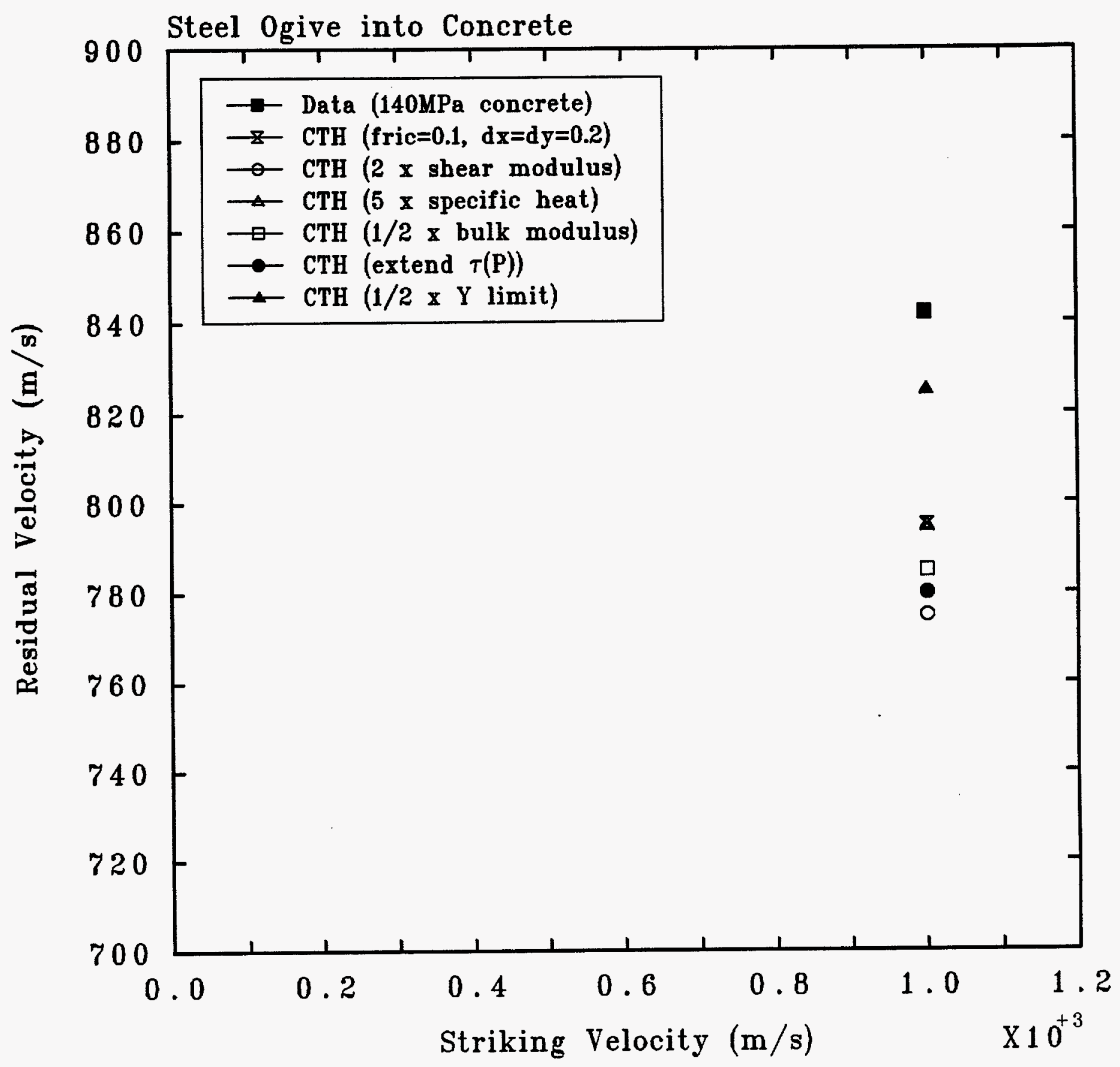

Figure 4.3.6. Residual Velocity Predicted by CTH when Concrete Material Properties are Varied - Ogival-Nosed Rods Penetrating $140 \mathrm{MPa}$ Concrete Targets at an Impact Velocity of $1000 \mathrm{~m} / \mathrm{s}$ 


\section{Summary and Conclusions}

Two series of metal penetration experiments and a series of concrete slab perforation tests were simulated with the CTH Eulerian code. The experiments involved penetration of 7075-T651 aluminum alloy targets by ogival-nosed (3CRH) projectiles, penetration of 6061-T651 aluminum alloy targets by hemispherical-nosed rods, and penetration of unreinforced concrete slabs by ogival-nosed (3CRH) projectiles. Target material constants were determined from independent material property tests. The projectiles were made of maraging steel in all cases and impact velocities for both target types covered the range from $\sim 300 \mathrm{~m} / \mathrm{s}$ to $\sim 1200 \mathrm{~m} / \mathrm{s}$. For the metal penetration experiments, depth of penetration was measured, while residual velocity of the projectile was measured for the concrete slab perforation tests. These data were compared with the CTH calculational results.

Our results demonstrate that CTH with the boundary-layer algorithm is well-suited to predict the global or "rigid-body" response of the penetrator. In all cases, the calculational results agree quite well with test data for the penetration depth or residual velocity $v s$ impact velocity over the entire velocity range in the experiments. Reasonable values of friction, in the $f \sim 0.0-0.1$ range, give calculational results which bracket the data. Friction was found to have more effect on penetration for the ogival-nosed projectiles than for the hemispherical-nosed rods.

The calculations used a new "boundary-layer" algorithm developed at Sandia to treat material interfaces in Eulerian codes. The necessity for including the boundary layer was demonstrated by results of calculations done without it, where the penetration of ogivalnosed penetrators impacting the aluminum target at high velocity was underpredicted by a factor of 2 .

We also found that that the Johnson-Holmquist ceramic model gives a good representation of the concrete response for the slab penetration problems, even though it neglects some well-known features (e.g., fracture, damage-induced anisotropy, porosity, etc.) which may be important for other problems. 


\section{Bibliography}

[1] J. M. McGlaun, S. L. Thompson, L. N. Kmetyk, and M. G. Elrick, "A Brief Description of the Three-Dimensional Shock Wave Physics Code CTH", SAND89-0607, Sandia National Laboratories, July 1990.

[2] S. A. Silling, "Eulerian Simulation of the Perforation of Aluminum Plates by Nondeforming Projectiles", SAND92-0493, Sandia National Laboratories, March 1992.

[3] S. A. Silling, "CTH Reference Manual: Boundary Layer Algorithm for Sliding Interfaces in Two Dimensions", SAND93-2487, Sandia National Laboratories, January 1994.

[4] M. J. Forrestal, V. K. Luk, Z. Rosenburg, N. S. Brar, "Penetration of 7075-T651 Aluminum Targets with Ogival-Nose Rods", Int. J. Solids Structures $\underline{29}$ 14/15 (1992), 1729-1736.

[5] M. J. Forrestal, N. S. Brar, V. K. Luk, "Penetration of Stain-Hardening Targets with Rigid Spherical-Nose Rods", J. App. Mech. 113 (1991), 7-10.

[6] S. J. Hanchek, M. J. Forrestal, E. R. Young, J. Q. Ehrgott, "Perforation of Concrete Slabs with $48 \mathrm{MPa}$ (7 ksi) and $140 \mathrm{MPa}$ (20 ksi) Unconfined Compressive Strengths", Int. J. Impact Engng. 121 (1992), 1-7.

[7] S. A. Silling, "CTH Reference Manual: Viscoplastic Models", SAND91-0292, Sandia National Laboratories, June 1991.

[8] S. A. Silling, "CTH Reference Manual: Johnson-Holmquist Ceramic Model", SAND92-0576, Sandia National Laboratories, September 1992. 


\section{A CTH Input Model for Penetration of Aluminum Targets by Ogival-Nosed Steel Rods at $1258 \mathrm{~m} / \mathrm{s}$}

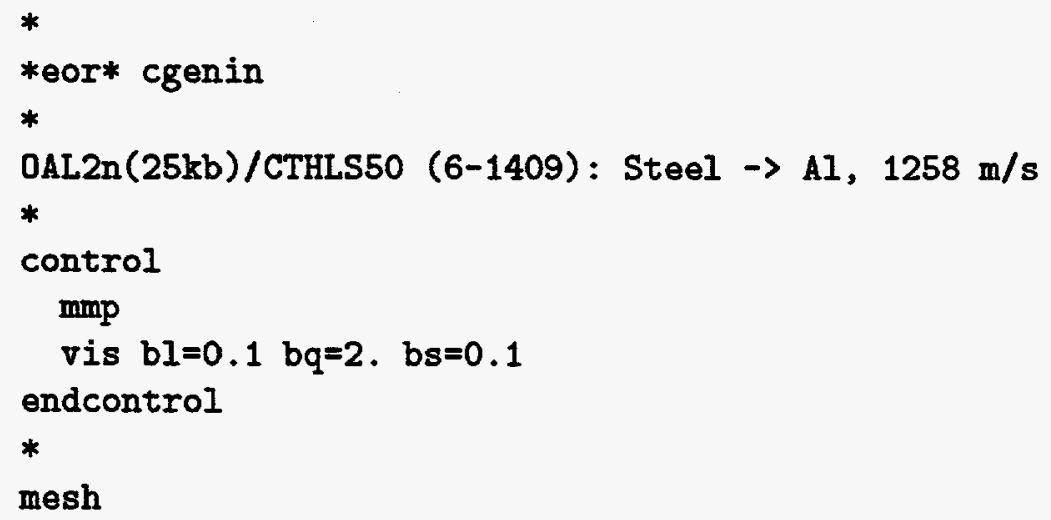

1. 1791 


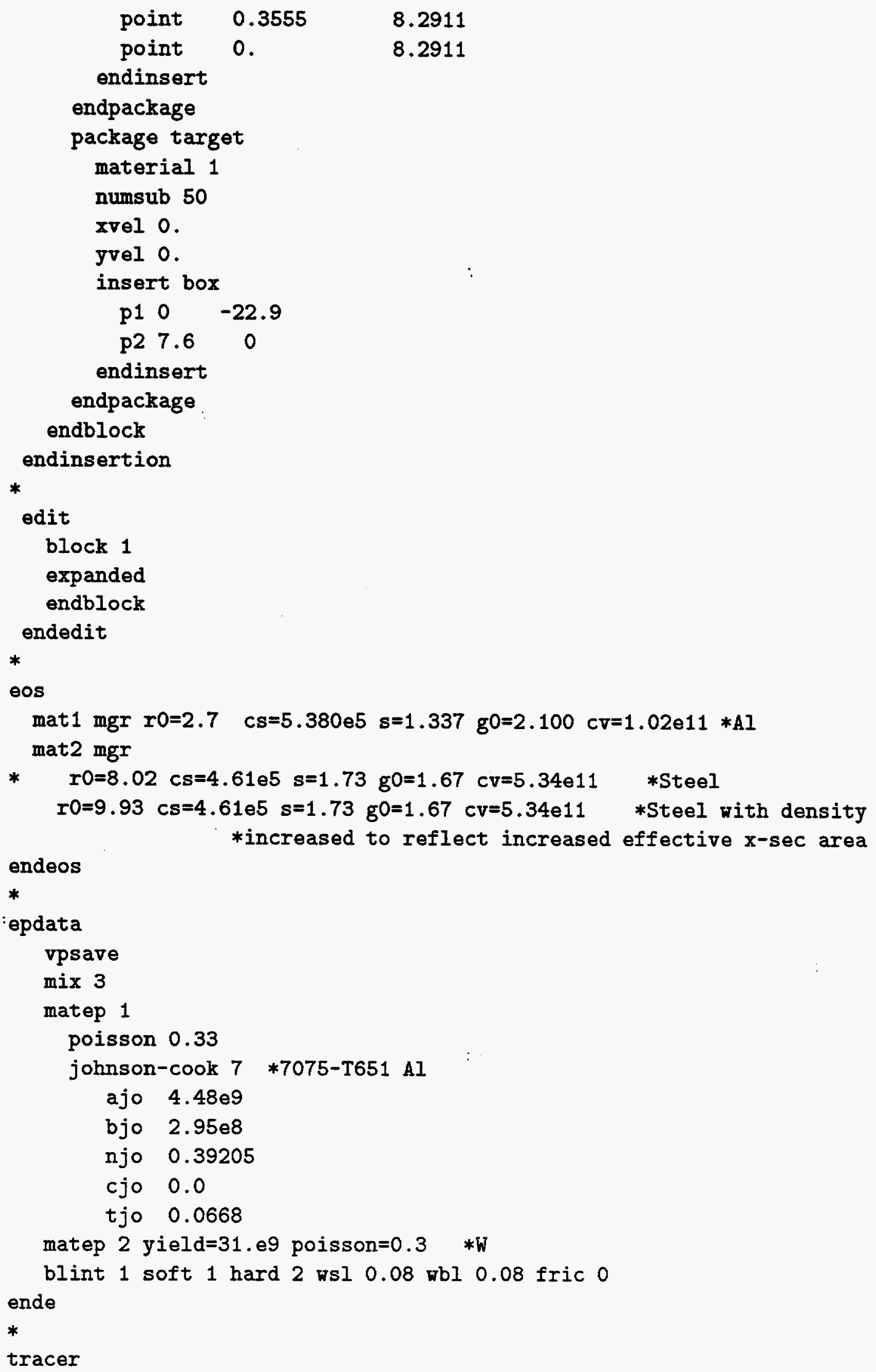


add 00.01 to $08.28 \mathrm{n} 6$

endt

*

*eor* cthin

*

OAL2n(25kb)/CTHLS50 (6-1409): Steel $\rightarrow$ Al, $1258 \mathrm{~m} / \mathrm{s}$

*

restart

* $\mathrm{nu}=2$

* time $=50 . e-6$

endr

*

control

$\min$

tstop $=400 \cdot 0 \mathrm{e}-6$

nscycle $=150000$

rdumpf $=3600$.

ntbad $=1000000$

endc

*

convet

interface=high_resolution

endc

*

edit

shortc

$c y=0 d c=1000$

ends

longt

$\operatorname{tim}=1 . e-6 \mathrm{dt}=1.0$

endl

histt

tim=0 dt $f=0 \cdot 1 e^{-6}$

htracer 1

htracer2

htracer 3

htracer4

htracer5

htracer6

endh

plott

tim $=0 \mathrm{dt}=20 \cdot 0 \mathrm{e}-6$

endp

ende

*

boundary

bhy 


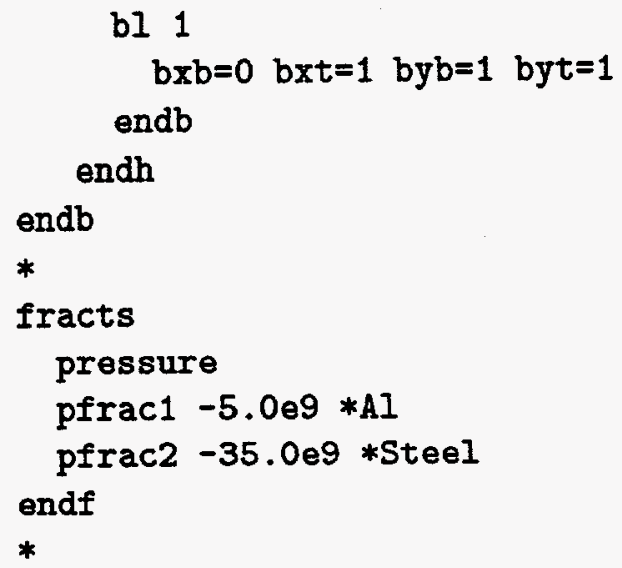




\section{B CTH Input Model for Penetration of Aluminum Targets by Hemispherical-Nosed Steel Rods at $1009 \mathrm{~m} / \mathrm{s}$}

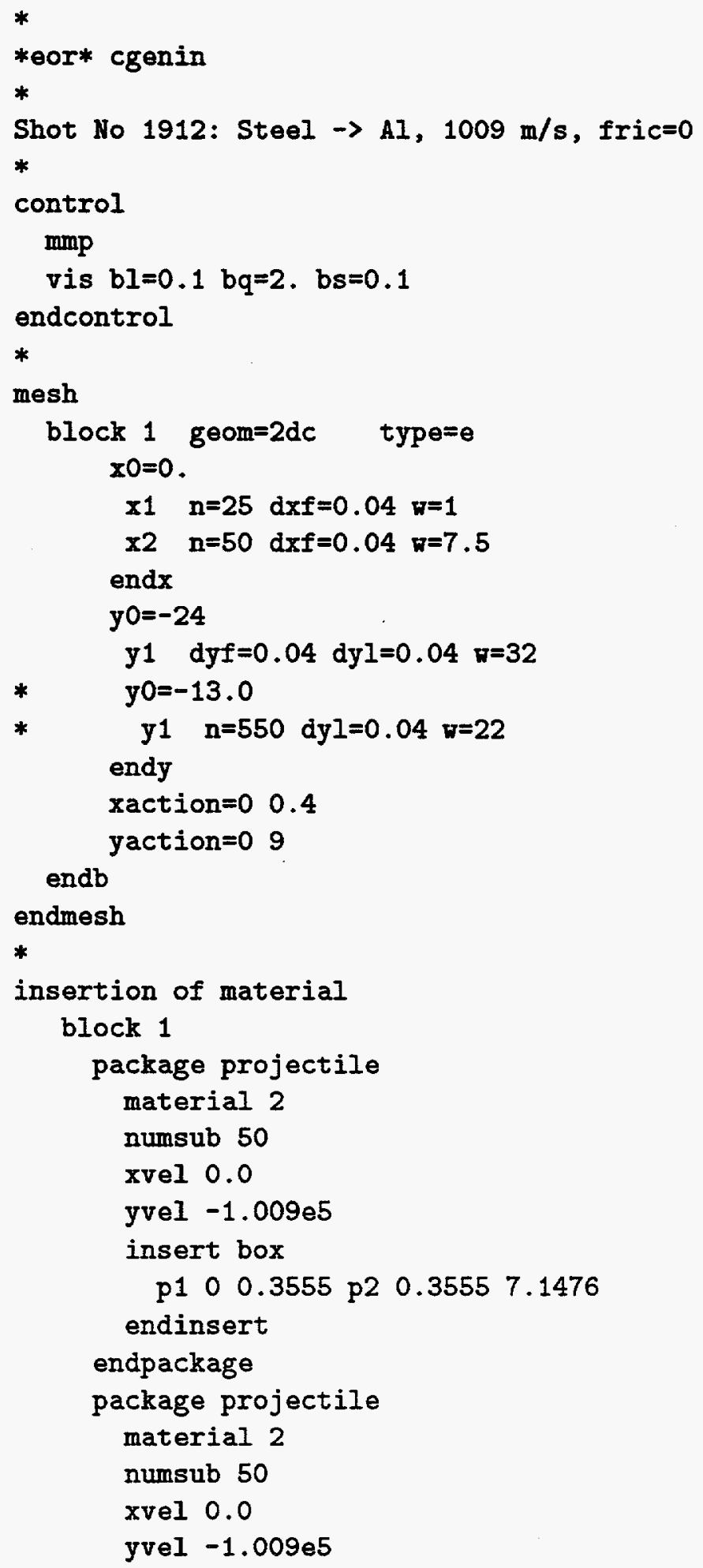




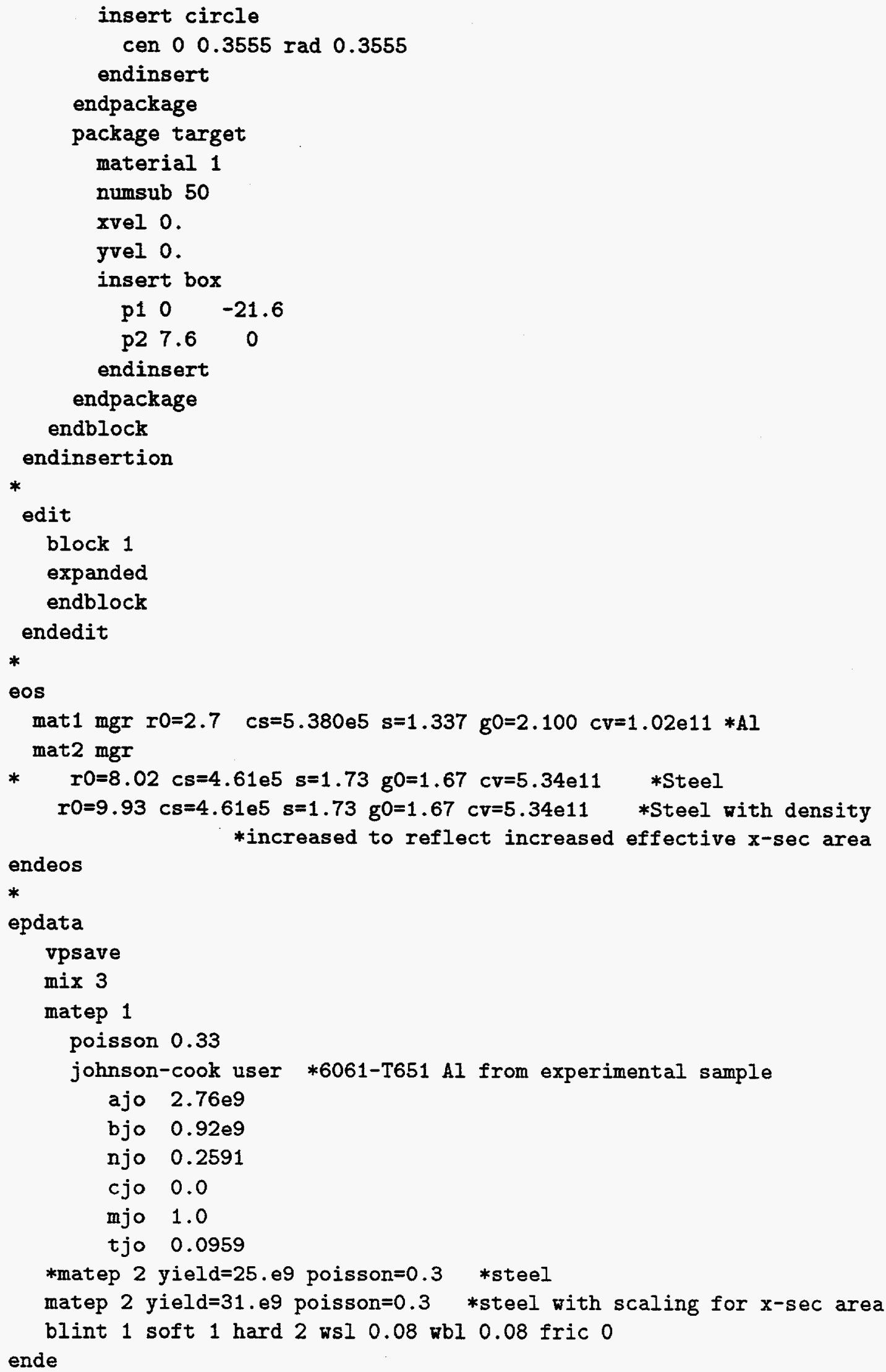




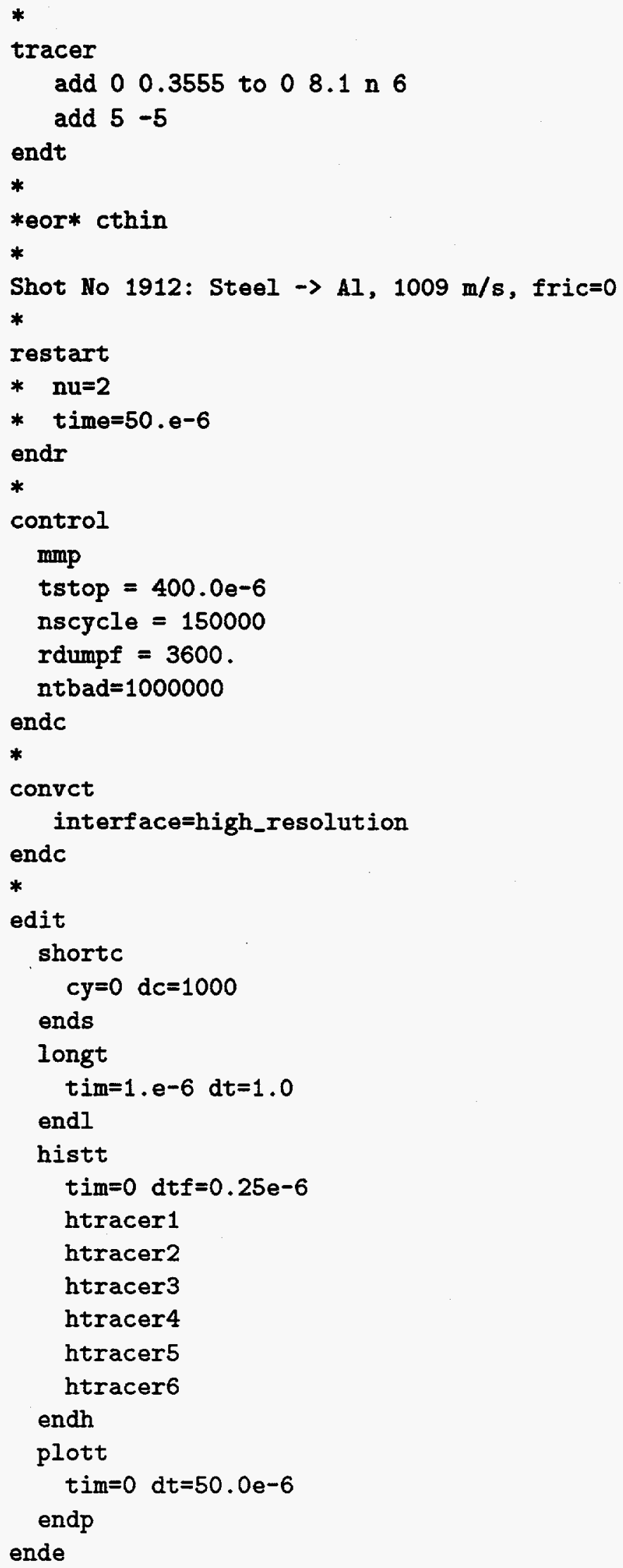


*

fragment

mat 1

ntracer 7

dcycle 50

endf

*

boundary

bhy

bl 1

$b x b=0 \quad b x t=1 \quad b y b=1$ byt=1

endb

endh

endb

*

fracts

pressure

pfrac1 $-10.0 e 9 * A 1$

pfrac2 $-35.0 e 9 *$ Steel

endf

* 


\section{CTH Input Model for Penetration of Concrete Targets by Ogival-Nosed Steel Rods at $1000 \mathrm{~m} / \mathrm{s}$}

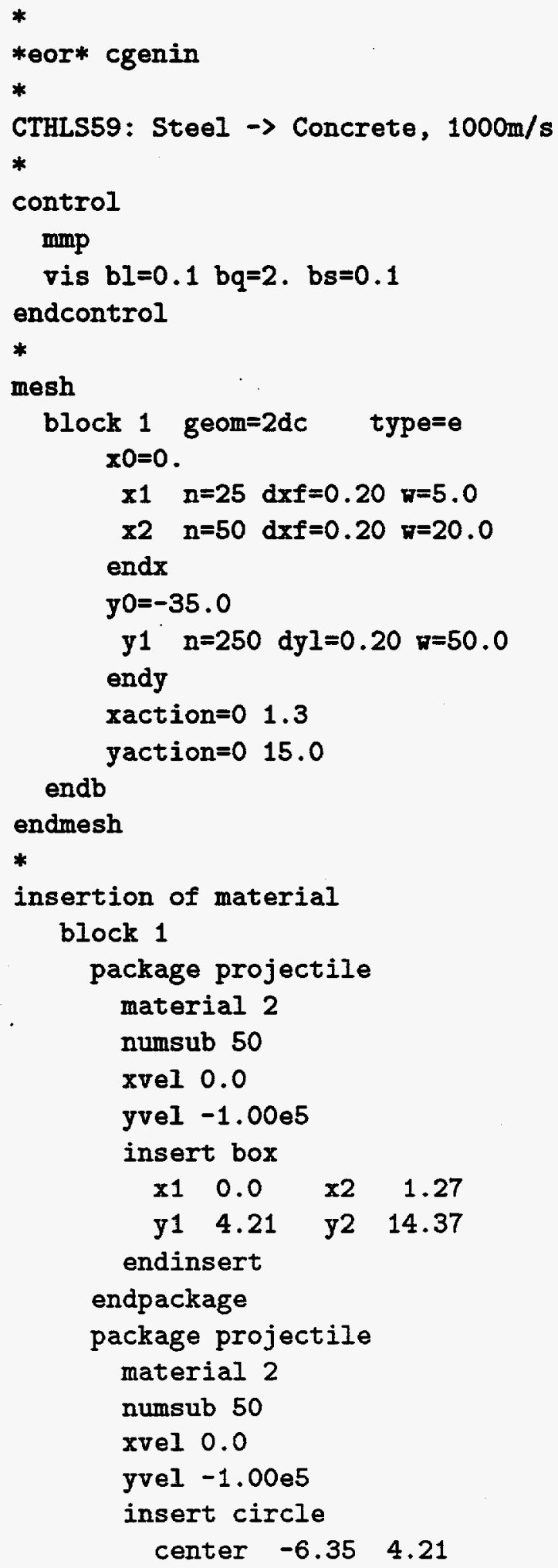




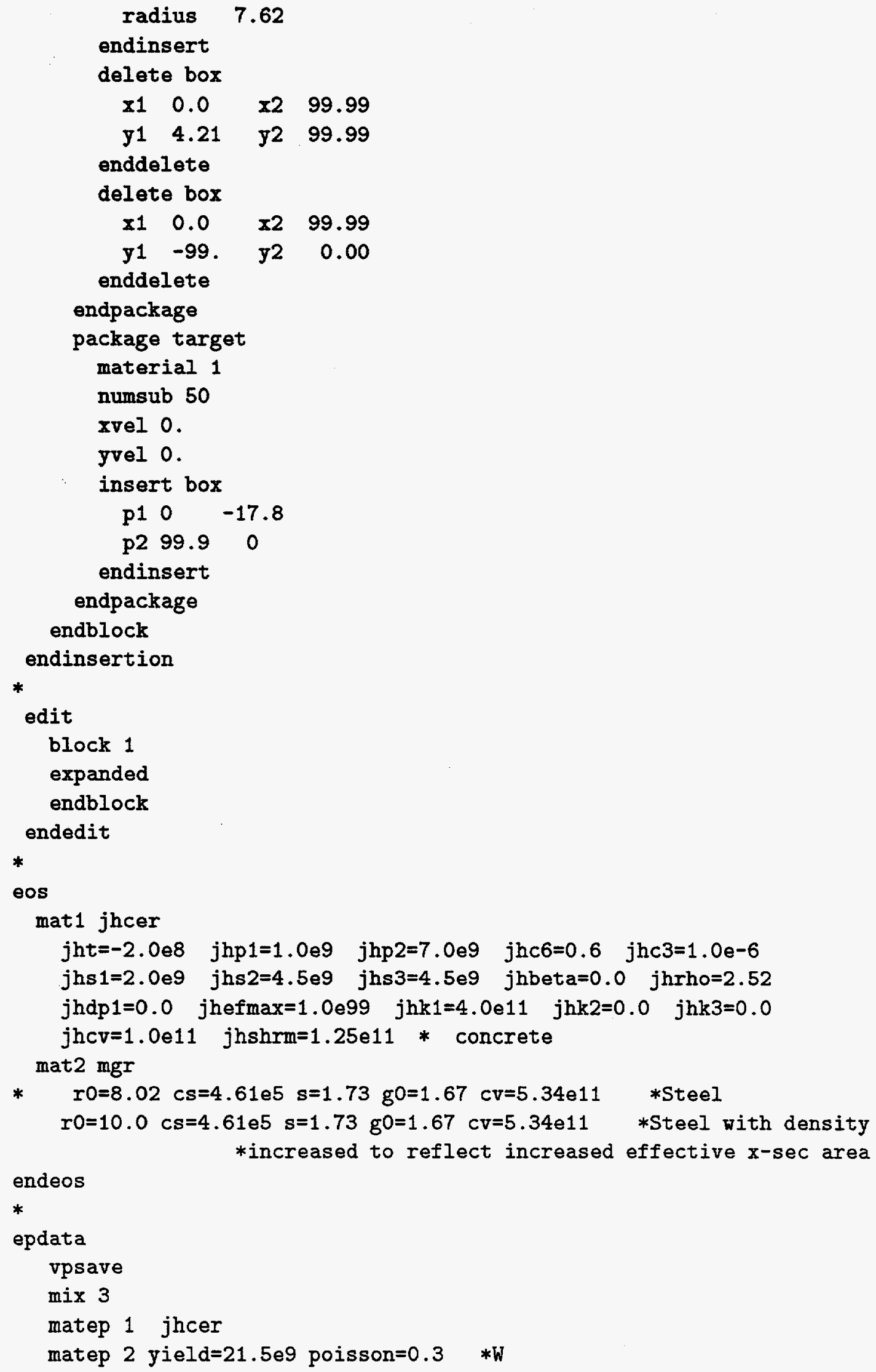


blint 1 soft 1 hard 2 wsl 0.30 vbl 0.30 fric 0.01

ende

*

tracer

add 00.01 to $014.35 \mathrm{n} 9$

endt

*

*eor* cthin

*

CTHLS59: Steel $\rightarrow$ Concrete, $1000 \mathrm{~m} / \mathrm{s}$

*

control

$\operatorname{minp}$

tstop $=399.0 e-6$

nscycle $=150000$

rdumpf $=3600$.

ntbad $=1000000$

endc

*

convet

interface=high_resolution

endc

*

edit

shortc

$c y=0 \quad d c=1000$

ends

longt

$\operatorname{tim}=1 \cdot e-6 \mathrm{dt}=1.0$

endl

histt

tim $=0$ dt $f=0.1 e-6$

htracer 1

htracer2

htracer3

htracer4

htracer5

htracer6

endh

plott

tim $=0 \mathrm{dt}=25 \cdot 0 \mathrm{e}-6$

endp

ende

*

boundary

bhy

bl 1 


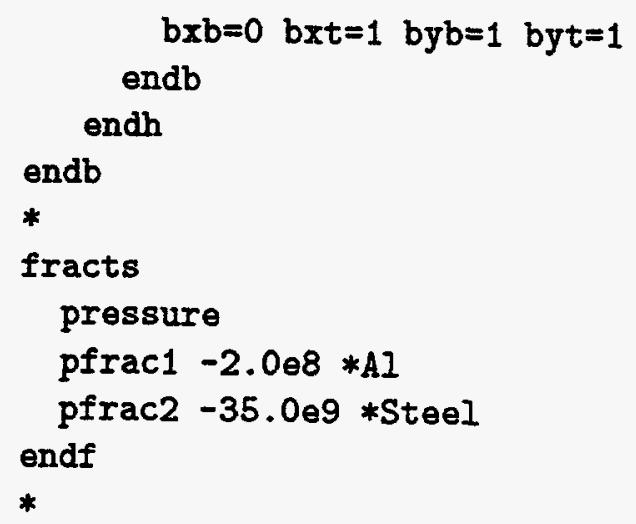


Report Distribution List:

M. D. Adley

U. S. Army Engineers

Waterways Experiment Station

Concrete Technology Division

3909 Halls Ferry Road

Vicksburg, MI 39180-6199

F. Allahdadi

Phillips Laboratory

PL/WSSD

Kirtland AFB, NM 87117-6008

Southwest Research Institute (2)

P.O. Drawer 28510

San Antonio, TX 78228-0510

Attn: C. E. Anderson \& J. D. Walker

Barry L. Bingham

Applied Research Associates, Inc.

4300 San Mateo Blvd. NE

Suite A220

Albuquerque, NM 87110

U. S. Army ARDEC (2)

SMCAR-AEE-WW, Bldg. 3022

Picatinny Arsenal, NJ 07806-5000

Attn: C. Chin \& E. Baker

Lockheed Missiles and Space Company (2)

Organization 89-10, Bldg. 157

P. O. Box 3504

Sunnyvale, CA 94088-3504

Attn: Y. Choo \& E. Matheson

Dwight Clark

Thiokol Corporation

Science \& Engineering Division

P. O. Box 707, Mailstop 280

Brigham City, Utah 84302-0707

Wright Laboratory (3)

WL/MNMW, Bldg. 13

Eglin AFB, FL 32542-5434

Attn: J. Collins, M. Nixon, J. C. Foster 
R. Hunt

Wright Laboratory

WL/MNSA

Eglin AFB, FL 32542-5434

Gordon R. Johnson

Alliant Techsystems Inc.

600 2nd Street NE (MN11-2925)

Hopkins, MN 55343

U. S. Army Research Laboratory (7)

AMSRL-WT-TC

Aberdeen Proving Ground MD 21005-5066

Attn: K. Kimsey, H. Meyer, G. Randers-Pehrson, J. Dehn,

Y. Huang, D. Scheffler, S. Segletes,

Eric Lundstrom

Naval Air Warfare Center

Weapons Division, Code 3261

China Lake, CA 93555

Naval Surface Warfare Center (3)

Code R14

10901 New Hampshire Ave.

Silver Spring, MD 20903-5000

Attn: H. Mair, W. Reed, \& P. Walters

Charles E. Needham

Maxwell/S-CUBED

2501 Yale SE

Suite 300

Albuquerque, NM 87106

Maj. William Oliver

U. S. Army Medical Corp

Armed Forces Institute of Pathology

Department of Cellular Biology

Washington, DC 20306-6000

D.L. Orphal

California Research \& Technology, Inc.

5117 Johnson Dr.

Pleasanton, CA 94588 
P. F. Radkowski, III

Radkowski Associates

P. O. Box 1121

Los Alamos, NM 87544

Teledyne Brown Engineering (2)

300 Sparkman Drive, MS/50

P. O. Box 070007

Huntsville, AL 35807-7007

Attn: B. Loper, M. White

Guy Spitale

Jet Propulsion Laboratory

California Institute of Technology

Reliability Engineering Section

4800 Oak Grove Drive

Pasadena, CA 91109

Los Alamos National Laboratory

Mail Station $\mathbf{5 0 0 0}$

P.O. Box 1663

Los Alamos, NM 87545

Attn: T. F. Adams, MS F663

Attn: S. T. Bennion, MS F663

Attn: W. Birchler, MS J576

Attn: M. W. Burkett, MS G787

Attn: E. J. Chapyak, MS F663

Attn: D. Mandell, MS F663

University of California

Lawrence Livermore National Laboratory

7000 East Ave.

P.O. Box 808

Livermore, CA 94550

Attn: M. J. Murphy, MS L-368

Attn: J. E. Reaugh, MS L-290

Attn: D. J. Steinberg, MS L-35

Attn: R. E. Tipton, MS L-35 


\section{Sandia National Laboratories}

0321 E. H. Barsis (1400)

0819 J. M. McGlaun (1431)

0819 K. G. Budge (1431)

0819 M. G. Elrick (1431)

0819 E. S. Hertel (1431)

1393 R. J. Lawrence (5609)

0819 J. S. Peery (1431)

0819 S. V. Petney (1431)

0819 A. C. Robinson (1431)

0819 T. G. Trucano (1431)

0820 P. Yarrington (1432) (10)

0820 R. L. Bell (1432)

0820 R. M. Brannon(1432)

0820 P. J. Chen (1432)

0820 H. E. Fang (1432)

0820 A. V. Farnsworth (1432)

0820 G. I. Kerley (1432)

0820 M. E. Kipp (1432)

0820 F. R. Norwood (1432)

0820 S. A. Silling (1432)

0820 P. A. Taylor (1432)

0821 P. L. Stanton (1433)

0821 J. A. Ang (1404)

0821 L. C. Chhabildas (1433)

0821 M. D. Furnish (1433)

0821 D. E. Grady (1433)

0437 J. W. Swegle (1562)

0100 Document Processing DOE/OSTI (7613-2) (10)

0745 S. L. Thompson (6418)

0745 L. N. Kmetyk (6418) (10)

0899 Technical Library (13414) (7)

0619 Technical Publications (13416)

9018 Central Technical Files (8523-2)

9042 G. A. Benedetti (8741)

9042 M. L. Chiesa (8741)

9042 L. E. Voelker (8741)

8742 J. J. Dike (8742)

9042 A. McDonald (8742)

9042 V. D. Revelli (8742)

9042 L. I. Weingarten (8742)

9043 M. L. Callabresi (8743)

9043 D. J. Bammann (8743)

0303 R. O. Nellums (9722)

0303 M. J. Forrestal (9723)

0303 J. T. Hitchcock (9723) 